\title{
Transcription analysis of recombinant industrial and laboratory Saccharomyces cerevisiae strains reveals the molecular basis for fermentation of glucose and xylose
}

\author{
Akinori Matsushika ${ }^{1 *}$, Tetsuya Goshima ${ }^{1}$ and Tamotsu Hoshino ${ }^{1,2}$
}

\begin{abstract}
Background: There has been much research on the bioconversion of xylose found in lignocellulosic biomass to ethanol by genetically engineered Saccharomyces cerevisiae. However, the rate of ethanol production from xylose in these xylose-utilizing yeast strains is quite low compared to their glucose fermentation. In this study, two diploid xylose-utilizing S. cerevisiae strains, the industrial strain MA-R4 and the laboratory strain MA-B4, were employed to investigate the differences between anaerobic fermentation of xylose and glucose, and general differences between recombinant yeast strains, through genome-wide transcription analysis.

Results: In MA-R4, many genes related to ergosterol biosynthesis were expressed more highly with glucose than with xylose. Additionally, these ergosterol-related genes had higher transcript levels in MA-R4 than in MA-B4 during glucose fermentation. During xylose fermentation, several genes related to central metabolic pathways that typically increase during growth on non-fermentable carbon sources were expressed at higher levels in both strains. Xylose did not fully repress the genes encoding enzymes of the tricarboxylic acid and respiratory pathways, even under anaerobic conditions. In addition, several genes involved in spore wall metabolism and the uptake of ammonium, which are closely related to the starvation response, and many stress-responsive genes mediated by Msn2/4p, as well as trehalose synthase genes, increased in expression when fermenting with xylose, irrespective of the yeast strain. We further observed that transcript levels of genes involved in xylose metabolism, membrane transport functions, and ATP synthesis were higher in MA-R4 than in MA-B4 when strains were fermented with glucose or xylose.
\end{abstract}

Conclusions: Our transcriptomic approach revealed the molecular events underlying the response to xylose or glucose and differences between MA-R4 and MA-B4. Xylose-utilizing S. cerevisiae strains may recognize xylose as a non-fermentable carbon source, which induces a starvation response and adaptation to oxidative stress, resulting in the increased expression of stress-response genes.

Keywords: Transcriptomics, DNA microarray, Saccharomyces cerevisiae, Xylose fermentation, Ethanol production

\footnotetext{
*Correspondence: a-matsushika@aist.go.jp

'Biomass Refinery Research Center (BRRC), National Institute of Advanced

Industrial Science and Technology (AIST), 3-11-32 Kagamiyama,

Higashi-Hiroshima, Hiroshima 739-0046, Japan

Full list of author information is available at the end of the article
} 


\section{Background}

Interest in renewable energy sources is increasing substantially as an alternative to conventional fossil energy. Ethanol biofuel produced from lignocellulosic biomass generated in the agricultural and forestry sectors is a promising renewable energy source [1]. The yeast Saccharomyces cerevisiae is the preferred organism for industrial ethanol production from sugar derived from starch and sucrose due to its high growth rate, rapid fermentation rate, and high ethanol productivity under anaerobic conditions, together with high tolerance for ethanol and low $\mathrm{pH}$. However, sugar derived from lignocellulosic biomass is a mixture of hexoses (primarily glucose) and pentoses (primarily xylose), and native strains of $S$. cerevisiae are unable to ferment xylose. Numerous studies have been conducted to develop metabolically engineered $S$. cerevisiae strains capable of utilizing xylose for ethanol production [2-6].

As $S$. cerevisiae is only able to metabolize xylulose, an isomerization product of xylose, the conversion of xylose to xylulose is crucial for the metabolic engineering of an efficient xylose-utilizing S. cerevisiae strain. Anaerobic xylose fermentation by $S$. cerevisiae was first demonstrated by heterologous expression of XYL1 and XYL2 genes encoding xylose reductase (XR) and xylitol dehydrogenase (XDH) from the yeast Scheffersomyces (Pichia) stipitis $[7,8]$. However, the resulting strains produce a considerable amount of xylitol as a by-product, thereby decreasing ethanol yields, mainly due to the difference in coenzyme specificities between XR (with NADPH) and XDH (with $\mathrm{NAD}^{+}$), which creates an intracellular redox imbalance [9]. Although heterologous expression of fungal or bacterial xylose isomerase (XI) that can directly convert xylose to xylulose is one solution to avoid cofactor imbalance in $S$. cerevisiae [10-13], many XI activities are too low to enable anaerobic growth on xylose, and the rate of xylose consumption is much lower in the XI-expressing S. cerevisiae strains than in the $\mathrm{XR}$ - and $\mathrm{XDH}$-expressing strains $[14,15]$. However, some recombinant XI-expressing S. cerevisiae strains that ferment xylose to ethanol at high conversion rates have been reported [16-18]. In particular, Zhou et al. [17] recently reported that combining metabolic and evolutionary engineering generates new XIexpressing strains of $S$. cerevisiae with a greatly improved anaerobic growth rate $\left(0.203 \mathrm{~h}^{-1}\right)$, xylose conversion rate $\left(1.866 \mathrm{~g} \mathrm{~g}^{-1} \mathrm{~h}^{-1}\right)$, and ethanol yield $(0.41 \mathrm{~g} / \mathrm{g})$.

Genome-wide analyses through synthetic genetic arrays, transcriptomics, proteomics, metabolomics, and fluxomics have been carried out to understand the genetic and physiological states of xylose metabolism [19-29]. For instance, we previously performed a comprehensive metabolome analysis using capillary electrophoresis time-of-flight mass spectrometry (CE-TOFMS) on the recombinant industrial S. cerevisiae strain MA-R4 during fermentation with different carbon sources, and demonstrated that low carbon flux through glycolysis from the PPP is one of the biggest factors restricting xylose utilization, and carbon and energy starvation conditions are induced in MA-R4 during fermentation with xylose [30]. Although these results provide a metabolic explanation for the low ethanol productivity on xylose compared to glucose, little is known about transcriptional differences between anaerobic glucose and xylose fermentation by MA-R4.

Industrial $S$. cerevisiae strains are generally superior ethanol producers in view of their inhibitory tolerance and high ethanol productivity compared to laboratory $S$. cerevisiae strains. For instance, industrial sake brewing yeasts have been selected for hundreds of years to have characteristics suitable for sake brewing, including high ethanol tolerance, high ethanol productivity, and high osmotic tolerance. To date, both laboratory and industrial $S$. cerevisiae strains have been metabolically engineered for improved xylose utilization [3]. In a previous study, we showed that the rates of aerobic xylose growth and anaerobic xylose fermentation of recombinant industrial strains, including MA-R4, were higher than those of recombinant laboratory strains [31]. In fermentations of mixed sugars containing glucose and xylose, the recombinant laboratory strains exhibited about a four-fold slower ethanol fermentation of both glucose and xylose as compared with the recombinant industrial strains [31]. Nevertheless, very little is known about the mechanisms responsible for the different characteristics between xylose-utilizing recombinant industrial and laboratory strains.

DNA microarray is a powerful tool to characterize differences in transcription levels as a function of cultivation conditions and strain differences, and to identify metabolic targets for the improvement of the rate and yield of ethanol production from xylose. Here, we carried out global transcriptional analysis based on DNA microarray to evaluate the differences in fermentation between the recombinant industrial strain, MA-R4, and the new recombinant laboratory strain, MA-B4, as well as the effects of two different carbon sources containing glucose and xylose. The aim of this study was to identify some of the genetic factors responsible for the high ethanol productivity on glucose compared to xylose, and for the high fermentation efficiency by industrial strains compared with laboratory strains. We identified certain genes and functional categories that are involved in ergosterol biosynthesis, central carbon metabolism, respiratory metabolism, hexose and other membrane transport systems, galactose metabolism, ATP synthesis, and response to starvation and stress.

\section{Results and discussion}

Anaerobic batch fermentations

To determine the effects of different carbon sources (xylose and glucose) and different sources of yeast 
(industrial and laboratory strains) on ethanol fermentation, fermentation by the recombinant $S$. cerevisiae strains MAR4 (industrial) and MA-B4 (laboratory) was performed anaerobically in YP-based media supplied with $40 \mathrm{~g} / \mathrm{L}$ glucose (YPD medium) and $40 \mathrm{~g} / \mathrm{L}$ xylose (YPX medium) in which aureobasidin A was not included. These strains exhibited stable recombinant enzyme activities and could be cultured in nonselective (YPD and YPX) media without significant loss of their xylose-fermenting ability for more than 10 generations (data not shown). In other words, these strains were stable and could grow on medium without aureobasidin $\mathrm{A}$ and without deletion of the integrated genes. As shown in Figure $1 \mathrm{~A}$ and B, MA-R4 and MA-B4 showed different fermentation patterns depending on the carbon source of the medium. Strain MA-R4 grew anaerobically on glucose with a specific growth rate of $0.37 \pm 0.01 \mathrm{~h}^{-1}$, whereas the growth rate of strain MA-B4 was $0.30 \pm 0.02 \mathrm{~h}^{-1}$. When xylose was provided as the sole carbon source, MA-R4 grew at a higher growth rate than MA-B4, with growth rates of $0.031 \pm 0.001 \mathrm{~h}^{-1}$ for MA-R4 and $0.020 \pm 0.001 \mathrm{~h}^{-1}$ for MA-B4. Thus, the specific growth rate of MA-R4 was more than 1.2-1.5-fold higher than that of MA-B4 in both YPD and YPX media. After a 7.5-h fermentation in YPD medium, the cell concentrations of MA-R4 and MA-B4 reached $13.7 \mathrm{~g} / \mathrm{L} \mathrm{DCW}$ and $12.7 \mathrm{~g} / \mathrm{L} \mathrm{DCW}$, respectively (Figure 1A). On the other hand, in YPX medium, the cell concentration of MA-R4 reached 9.35 g/L DCW after a 48-h fermentation, while that of MA-B4 reached $8.29 \mathrm{~g} / \mathrm{L} \mathrm{DCW}$ after a 56 -h fermentation (Figure 1B). Biomass yields calculated from these cell concentrations of MA-R4 were 12-18\% higher than those of MA-B4 in fermentation using YPD and YPX media. Thus, MA-R4 was apparently capable of utilizing complex media components slightly more efficiently for biomass and growth than MA-B4.

The rates of maximum specific glucose consumption and maximum specific ethanol production were similar in MA-R4 and MA-B4 in fermentation with YPD medium (Table 1). The maximum ethanol concentrations achieved by both MA-R4 and MA-B4 were approximately $18.6 \mathrm{~g} / \mathrm{L}$ after a 7.5-h fermentation in YPD medium (Figure 1A). After $7.5 \mathrm{~h}$ of fermentation with YPD, the ethanol yield per gram of consumed glucose (g/g) by MA-R4 was identical $(0.46 \mathrm{~g} / \mathrm{g}: 89-90 \%$ of the theoretical yield) with that by MA-B4 (Table 1). Thus, it appears that both strains had almost identical ethanol production capabilities during glucose fermentation with respect to the maximum production rate, yield, and maximum titer of ethanol. Meanwhile, the specific xylose consumption rate was $31 \%$ higher in MA-R4 (0.12 g-xylose/g-DCW/h) than in MAB4 (0.090 g-xylose/g-DCW/h) (Table 1). After $72 \mathrm{~h}$ of fermentation using YPX medium, MA-R4 metabolized almost all the xylose and produced $13.5 \mathrm{~g} / \mathrm{L}$ of ethanol; however, xylose fermentation by MA-B4 was not completed within $72 \mathrm{~h}$ (Figure 1B). MA-R4 had a 36\% higher rate of maximum specific ethanol production than MAB4 in fermentation with YPX medium (Table 1). The maximum specific ethanol production rates of both strains achieved in fermentation with YPX were 91-93\% lower than those with YPD (Table 1), which is consistent with our previous results from fermentation with glucose or xylose alone [30,32]. After $72 \mathrm{~h}$ of fermentation with YPX, the ethanol yield $(0.34 \mathrm{~g} / \mathrm{g})$ of MA-R4 was higher than that $(0.27 \mathrm{~g} / \mathrm{g})$ of MA-B4 (Table 1$)$. The ethanol yields in YPX by MA-R4 and MA-B4 corresponded to 66 and 52\% of the theoretical yield, respectively. Thus, the production rate and yield of ethanol from xylose is more strongly
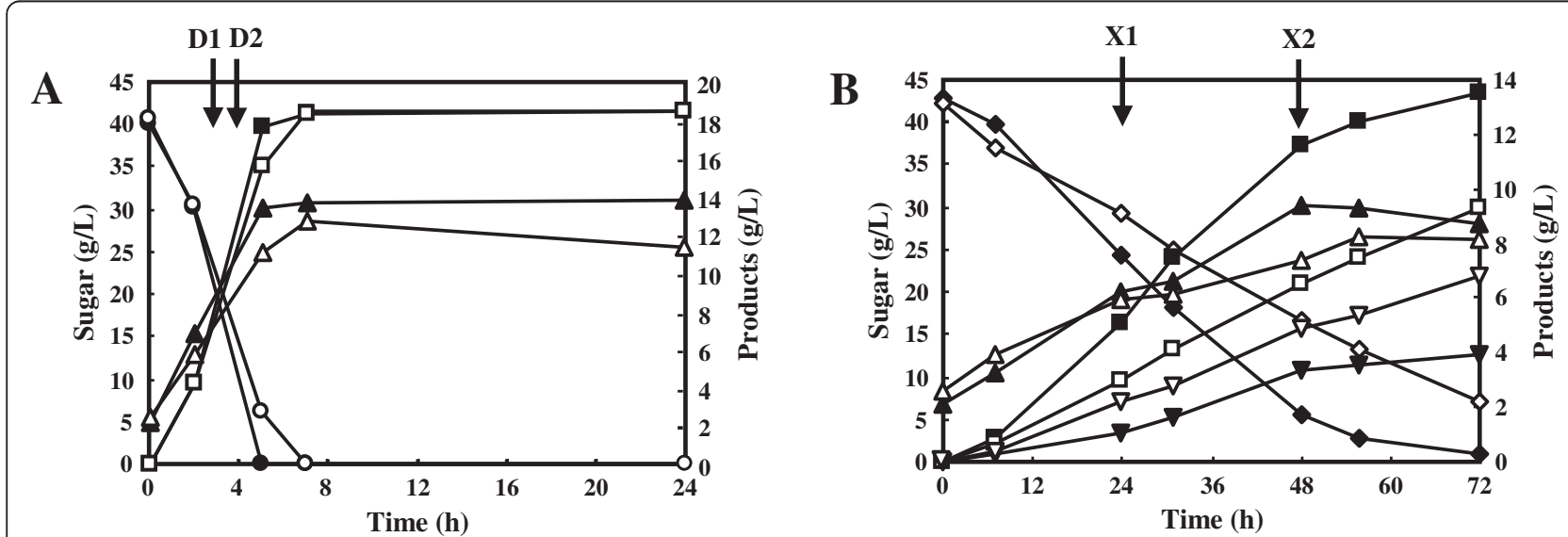

Figure 1 Time-dependent batch fermentation profiles of glucose consumption (circles), xylose consumption (diamonds), ethanol production (squares), dry cell weight (triangles), and xylitol excretion (inverted triangles) by recombinant S. cerevisiae, MA-R4 (closed symbols) and MA-B4 (open symbols), in YPD medium containing $40 \mathrm{~g} / \mathrm{L}$ glucose (A) and YPX medium containing $40 \mathrm{~g} / \mathrm{L}$ xylose (B) under anaerobic conditions. Small amounts of glycerol and acetic acid are not shown (see text). Data points represent the averages of three independent experiments. The arrows (denoted by D1, D2, X1, and X2) indicate times at which samples were taken for transcriptome analysis. 
Table 1 Comparison of fermentation performance of Sn cerevisiae strains MA-R4 and MA-B4 in anaerobic batch fermentations with YPD and YPX media

\begin{tabular}{|c|c|c|c|c|c|c|c|c|c|}
\hline Strain & Medium & $\begin{array}{l}\text { Max. specific } \\
\text { glucose } \\
\text { consumption } \\
\text { rate } \\
\text { (g-glucose/ } \\
\text { g-DCW/h) }\end{array}$ & $\begin{array}{l}\text { Max. specific } \\
\text { xylose } \\
\text { consumption } \\
\text { rate } \\
\text { (g-xylose/ } \\
\text { g-DCW/h) }\end{array}$ & $\begin{array}{l}\text { Max. specific } \\
\text { ethanol } \\
\text { production } \\
\text { rate } \\
\text { (g-ethanol/ } \\
\text { g-DCW/h) }\end{array}$ & $\begin{array}{l}\text { Biomass yield } \\
\text { (g-DCW/ } \\
\text { g-consumed } \\
\text { total sugar) }\end{array}$ & $\begin{array}{l}\text { Ethanol yield } \\
\text { (g-ethanol/ } \\
\text { g-consumed } \\
\text { total sugar) }\end{array}$ & $\begin{array}{l}\text { Xylitol yield } \\
\text { (g-xylitol/ } \\
\text { g-consumed } \\
\text { xylose) }\end{array}$ & $\begin{array}{l}\text { Glycerol yield } \\
\text { (g-glycerol/ } \\
\text { g-consumed } \\
\text { total sugar) }\end{array}$ & $\begin{array}{l}\text { Acetic acid } \\
\text { yield } \\
\text { (g-acetic acid/ } \\
\text { g-consumed } \\
\text { total sugar) }\end{array}$ \\
\hline \multirow[t]{2}{*}{ MA-R4 } & YPD & $0.60 \pm 0.06$ & $\mathrm{ND}$ & $0.28 \pm 0.02$ & $0.29 \pm 0.00$ & $0.46 \pm 0.01$ & ND & $0.026 \pm 0.001$ & $0.010 \pm 0.001$ \\
\hline & YPX & ND & $0.12 \pm 0.01$ & $0.026 \pm 0.001$ & $0.20 \pm 0.00$ & $0.34 \pm 0.01$ & $0.098 \pm 0.001$ & $0.077 \pm 0.004$ & $0.012 \pm 0.001$ \\
\hline \multirow[t]{2}{*}{ MA-B4 } & YPD & $0.58 \pm 0.04$ & ND & $0.26 \pm 0.02$ & $0.26 \pm 0.01$ & $0.46 \pm 0.00$ & ND & $0.019 \pm 0.001$ & $0.012 \pm 0.000$ \\
\hline & YPX & ND & $0.09 \pm 0.01$ & $0.019 \pm 0.001$ & $0.17 \pm 0.00$ & $0.27 \pm 0.01$ & $0.20 \pm 0.00$ & $0.043 \pm 0.001$ & $0.011 \pm 0.000$ \\
\hline
\end{tabular}

affected than that from glucose between the two recombinant strains.

In both strains, glycerol accumulation was maintained at a level lower than $1.1 \mathrm{~g} / \mathrm{L}$ during glucose fermentation, and at a level lower than $3.1 \mathrm{~g} / \mathrm{L}$ during xylose fermentation. A minimal amount of acetic acid (no more than $0.7 \mathrm{~g} / \mathrm{L}$ ) was produced mainly during glucose fermentation. After $72 \mathrm{~h}$ of fermentation with YPX, MA-R4 and MA-B4 excreted 3.94 and $6.81 \mathrm{~g} / \mathrm{L}$ of xylitol, respectively (Figure 1B). Compared with MA-B4, MA-R4 showed a $42 \%$ decrease in xylitol excretion with a $45 \%$ increase in ethanol production. As shown in Table 1, the xylitol yield doubled from $0.098 \mathrm{~g}$ of xylitol/g of consumed xylose in MA-R4 to $0.20 \mathrm{~g} / \mathrm{g}$ in MA-B4. The lower ethanol yield of MA-B4 was apparently directly related to its very high xylitol yield. Meanwhile, for both media, the glycerol yield was lower in MA-B4 than in MA-R4 (Table 1). The acetic acid yield of both strains was relatively constant during fermentation using YPD and YPX media (Table 1).

\section{Overview of the microarray data}

The global transcriptional responses of MA-R4 and MA-B4 to changes in carbon sources, including glucose and xylose, were analyzed by using DNA microarrays at specific time-points during $72 \mathrm{~h}$ of fermentation. After the initiation of glucose fermentation using YPD medium, samples of MA-R4 and MA-B4 were harvested at $3 \mathrm{~h}$ and $4 \mathrm{~h}$, which were denoted as D1 and D2 stages, respectively (Figure 1A). Samples of MA-R4 and MA-B4 were harvested at $24 \mathrm{~h}$ and $48 \mathrm{~h}$ (denoted as $\mathrm{X} 1$ and $X 2$ stages in Figure 1B, respectively) from the start of the cultures containing xylose alone (YPX medium). Thus, these samples were prepared from cells grown until each of the two recombinant $S$. cerevisiae strains had consumed approximately half of each sugar in single-sugar fermentations (glucose or xylose). After the sampling, total RNA was extracted, and then DNA microarray analysis was carried out as described in the Methods section below. For each strain and condition, transcript levels were normalized and quantified by using duplicate (dyeswap) experiments.

The microarray data were included in the following four relevant pairwise comparisons of gene expression levels: MA-R4 utilizing xylose vs. MA-R4 utilizing glucose (Comparison $1=\mathrm{C} 1$ ); MA-B4 utilizing xylose vs. MA-B4 utilizing glucose (Comparison $2=\mathrm{C} 2$ ); MA-R4 utilizing xylose vs. MA-B4 utilizing xylose (Comparison $3=\mathrm{C} 3$ ); and MA-R4 utilizing glucose vs. MA-B4 utilizing glucose (Comparison $4=\mathrm{C} 4$ ). Next, subsets of genes were identified according to the following criteria: (a) up-regulated genes that changed expression levels on xylose compared with glucose between MA-R4 and MA-B4 (C1 \& C2 up, Figure 2A), (b) down-regulated genes that changed expression levels on xylose compared with glucose between MA-R4 and MA-B4 (C1 \& C2 down, Figure 2B), (c) upregulated genes that changed expression levels in MA-R4 compared to MA-B4 on xylose and glucose (C3 \& C4 up, Figure $2 \mathrm{C}$ ), and (d) down-regulated genes that changed expression levels in MA-R4 compared to MA-B4 on xylose and glucose (C3 \& C4 down, Figure 2D). A relatively large number of genes, 680 and 712, were up-regulated and down-regulated in both MA-R4 and MA-B4 on xylose compared to glucose, respectively (Figure 2A and B). In contrast, relatively few genes, 68 and 195, were up-regulated and down-regulated on both xylose and glucose in MA-R4 compared to MA-B4, respectively (Figure $2 \mathrm{C}$ and $\mathrm{D}$ ).

\section{Gene ontology (GO) terms}

Using the DNA microarray data obtained, we identified the functional categories of genes with altered expression within the previously described groups $(\mathrm{C} 1, \mathrm{C} 2, \mathrm{C} 3$, and $\mathrm{C} 4$ ). In general, the identified functional categories would be expected to reflect the functions involved in xylose-utilizing $S$. cerevisiae. In this study, the functions of the gene products were classified by using the gene ontology (GO) terms (http://www.geneontology.org/). Table 2 shows the top ten GO terms $(p<0.01)$ of genes with up-regulated and down-regulated expressions identified 
A

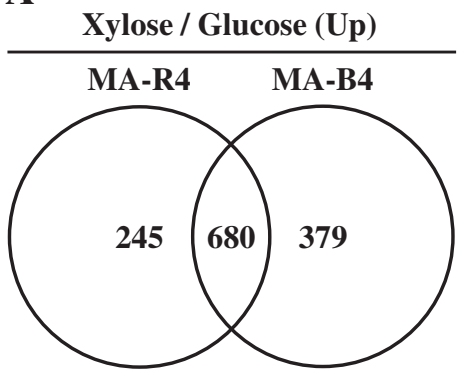

C

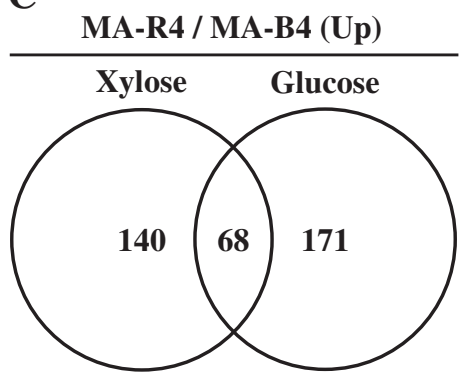

B

Xylose / Glucose (Down)

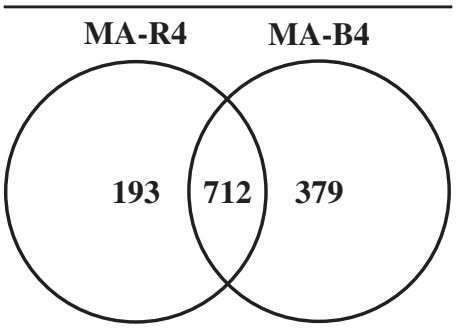

D

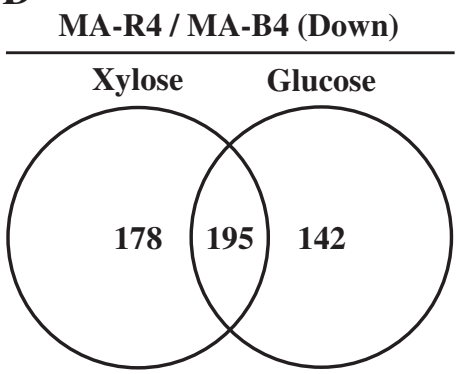

Figure 2 Venn diagram of common genes with significantly increased expression levels in xylose culture compared to glucose (A), with significantly decreased expression levels in xylose culture compared to glucose (B), with significantly increased expression levels in MA-R4 compared to MA-B4 (C), and with significantly decreased expression levels in MA-R4 compared to MA-B4 (D). The total number inside each circle represents the number of genes showing a $>2$-fold change with carbon source or yeast strain in that particular comparison, i.e. 925 up-regulated and 905 down-regulated genes for MA-R4 Xylose/Glucose (C1, Table 2), 1059 up-regulated and 1091 down-regulated genes for MA-B4 Xylose/Glucose (C2, Table 2), 208 up-regulated and 373 down-regulated genes for Xylose MA-R4/MA-B4 (C3, Table 2), and 239 up-regulated and 337 down-regulated genes for Glucose MA-R4/MA-B4 (C4, Table 2).

within the four pairwise comparisons. If GO terms with multiple synonyms were identified, only the most significant term was listed. In the pairwise comparisons of $\mathrm{C} 1$ and $\mathrm{C} 2$, many similar GO terms for the up-regulated and down-regulated genes were overrepresented. The GO terms "response to chemical stimulus", "oxidoreductase activity", and "generation of precursor metabolites and energy" for the up-regulated genes were overrepresented in both $\mathrm{C} 1$ and $\mathrm{C} 2$ comparisons. Moreover, the following $\mathrm{GO}$ terms for the down-regulated genes were overrepresented in both $\mathrm{C} 1$ and $\mathrm{C} 2$ comparisons: "intracellular part", "cytoplasm", "cellular process", "intracellular organelle", "metabolic process", "cellular metabolic process", "primary metabolic process", and "macromolecule metabolic process". These GO terms include genes involved in the biosynthesis of ribosomes and translation. Interestingly, processes related to amino acid metabolism for the up-regulated genes were overrepresented in the C3 comparison, while processes related to carbohydrate metabolism for the up-regulated genes were overrepresented in the $\mathrm{C} 2$ comparison. Increased expression of genes for protein synthesis (in both $\mathrm{C} 1$ and $\mathrm{C} 2$ comparisons) and amino acid synthesis (in the C3 comparison) appears to correlate directly to the efficiency of anaerobic growth. In addition, the GO terms "oxidoreductase activity" and "lipid metabolic process" were up-regulated by glucose in MA-R4 compared to
MA-B4 (C4 comparison). The GO term "lipid metabolic process" may be related to genes involved in ergosterol synthesis, as mentioned in the following subsection. On the other hand, no overrepresented GO terms for downregulated genes in either $\mathrm{C} 3$ or $\mathrm{C} 4$ comparisons could be found.

\section{Expression of ergosterol synthesis genes}

Sterols like ergosterol are known to play a structural role in membrane integrity, and ergosterol synthesis requires molecular oxygen. We found that the expression of several genes involved in ergosterol synthesis were significantly up-regulated during glucose fermentation in MA-R4 (Table 3). In addition, MA-R4 had higher expression levels of genes related to ergosterol biosynthesis than MA-B4 in fermentation with glucose (Table 3). These results suggest that during glucose fermentation, cellular ergosterol levels in MA-R4 are higher than in MA-B4, and that MA-R4 has a higher ergosterol content in fermentation with glucose than with xylose. These genes encode the enzymes that act both upstream and downstream of ergosterol biosynthesis (e.g., ERG10, HMG1, ERG1, and ERG2). ERG10 encodes acetyl-CoA C-acetyltransferase, which catalyzes the first step of sterol biosynthesis [33]. HMG1 encodes 3-hydroxy-3-methylglutaryl-CoA reductase, which catalyzes the conversion of 3-hydroxy-3- 
Table 2 The top ten gene ontology (GO) terms identified within four pairwise comparisons

\begin{tabular}{|c|c|c|c|c|c|c|}
\hline Comparison & Regulation & GO accession & GO term & $n$ & $\%$ & $p$-value \\
\hline \multirow[t]{15}{*}{ MA-R4 xylose/glucose (C1) } & \multirow[t]{5}{*}{ Up } & GO:0050896 & Response to stimulus & 174 & 67.4 & $5.60 \mathrm{E}-06$ \\
\hline & & GO:0006950 & Response to stress & 123 & 47.7 & $6.50 \mathrm{E}-05$ \\
\hline & & GO:0042221 & Response to chemical stimulus & 95 & 36.8 & $1.36 \mathrm{E}-03$ \\
\hline & & GO:0016491 & Oxidoreductase activity & 79 & 30.6 & $1.14 \mathrm{E}-06$ \\
\hline & & GO:0006091 & Generation of precursor metabolites and energy & 57 & 22.1 & $4.38 \mathrm{E}-05$ \\
\hline & \multirow[t]{10}{*}{ Down } & GO:0044424 & Intracellular part & 656 & 95.8 & $6.83 \mathrm{E}-04$ \\
\hline & & GO:0005737 & Cytoplasm & 500 & 73.0 & $5.16 \mathrm{E}-06$ \\
\hline & & GO:0009987 & Cellular process & 480 & 70.1 & $1.99 \mathrm{E}-06$ \\
\hline & & GO:0043229 & Intracellular organelle & 410 & 59.9 & $5.18 \mathrm{E}-03$ \\
\hline & & GO:0008152 & Metabolic process & 390 & 56.9 & $3.36 \mathrm{E}-09$ \\
\hline & & GO:0044237 & Cellular metabolic process & 390 & 56.9 & $1.91 \mathrm{E}-10$ \\
\hline & & GO:0044238 & Primary metabolic process & 374 & 54.6 & $3.26 \mathrm{E}-10$ \\
\hline & & GO:0043170 & Macromolecule metabolic process & 321 & 46.9 & $1.52 \mathrm{E}-07$ \\
\hline & & GO:0043283 & Biopolymer metabolic process & 321 & 46.9 & $7.22 \mathrm{E}-07$ \\
\hline & & GO:0006996 & Organelle organization & 263 & 38.4 & $1.94 \mathrm{E}-08$ \\
\hline \multirow[t]{14}{*}{ MA-B4 xylose/glucose (C2) } & \multirow[t]{4}{*}{ Up } & GO:0042221 & Response to chemical stimulus & 105 & 40.9 & $3.14 \mathrm{E}-08$ \\
\hline & & GO:0016491 & Oxidoreductase activity & 93 & 36.2 & $2.78 \mathrm{E}-08$ \\
\hline & & GO:0005975 & Carbohydrate metabolic process & 76 & 29.6 & $3.14 \mathrm{E}-08$ \\
\hline & & GO:0006091 & Generation of precursor metabolites and energy & 61 & 23.7 & 4.64E-08 \\
\hline & \multirow[t]{10}{*}{ Down } & GO:0044424 & Intracellular part & 852 & 95.9 & 1.17E-13 \\
\hline & & GO:0044464 & Cell part & 611 & 68.8 & $6.56 \mathrm{E}-11$ \\
\hline & & GO:0009987 & Cellular process & 611 & 68.8 & 4.06E-14 \\
\hline & & GO:0005737 & Cytoplasm & 609 & 68.6 & $6.14 \mathrm{E}-06$ \\
\hline & & GO:0043229 & Intracellular organelle & 534 & 60.1 & $3.13 \mathrm{E}-05$ \\
\hline & & GO:0008152 & Metabolic process & 474 & 53.4 & 2.14E-11 \\
\hline & & GO:0044237 & Cellular metabolic process & 474 & 53.4 & $8.13 \mathrm{E}-20$ \\
\hline & & GO:0044238 & Primary metabolic process & 457 & 51.5 & 4.88E-12 \\
\hline & & GO:0005634 & Nucleus & 404 & 45.5 & 2.87E-03 \\
\hline & & GO:0043170 & Macromolecule metabolic process & 382 & 43.0 & $1.34 \mathrm{E}-07$ \\
\hline \multirow[t]{2}{*}{ Xylose MA-R4/MA-B4 (C3) } & Up & GO:0006520 & Cellular amino acid metabolic process & 26 & 100 & $3.73 \mathrm{E}-04$ \\
\hline & Down & ND & ND & ND & ND & ND \\
\hline \multirow[t]{3}{*}{ Glucose MA-R4/MA-B4 (C4) } & \multirow[t]{2}{*}{ Up } & GO:0016491 & Oxidoreductase activity & 33 & 61.1 & $2.54 \mathrm{E}-05$ \\
\hline & & GO:0006629 & Lipid metabolic process & 32 & 59.3 & $2.54 \mathrm{E}-05$ \\
\hline & Down & ND & ND & ND & ND & ND \\
\hline
\end{tabular}

Up- and down-regulated gene ontology (GO) terms identified within four comparisons C1-C4. $n$ is the number of the genes with the specified function, \% is the percentage of the genes in the comparison with the specified function, and $p$-value is the binomial distribution probability. If no significantly over-represented GO terms were found, this was indicated by "ND" for "not detected".

methylglutaryl-CoA to mevalonate, a rate-limiting step of sterol biosynthesis in S. cerevisiae [34]. ERG1 encodes squalene epoxidase, which plays an essential role in the ergosterol biosynthesis pathway [35]. ERG2 encodes C-8 sterol isomerase, which is responsible for the isomerization of the $\mathrm{B}$ ring double bond from the 8 to the 7 position [36]. In MA-R4, ERG2 was particularly expressed at high levels during glucose fermentation, and its expression level was induced more than 14-fold (Table 3). Thus, the elevated transcription of ergosterol-related genes was specifically seen in MA-R4 during glucose fermentation.

Ergosterol, as well as unsaturated fatty acids, is an essential medium component for anaerobic growth of $S$. cerevisiae [37]. Ergosterol is also important in the ethanol tolerance of yeasts, since deletion of genes in ergosterol biosynthesis prevents proliferation and fermentation of sugars in the presence of moderate ethanol concentrations that are normally tolerated [38]. Taken 
Table 3 Expression levels of genes involved in ergosterol biosynthesis

\begin{tabular}{|c|c|c|c|c|c|c|}
\hline \multirow[t]{2}{*}{ ORF } & \multirow[t]{2}{*}{ Gene } & \multicolumn{2}{|c|}{ MA-R4 xylose/glucose (C1) } & \multicolumn{2}{|c|}{ Glucose MA-R4/MA-B4 (C4) } & \multirow[t]{2}{*}{ Description } \\
\hline & & (C1-1) & (C1-2) & (C4-1) & $(\mathrm{C} 4-2)$ & \\
\hline YPL028W & ERG10 & -9.74 & -11.19 & 4.26 & 3.00 & Acetyl-CoA C-acetyltransferase \\
\hline YML126C & ERG13 & -9.74 & -11.19 & 4.03 & 3.65 & 3-Hydroxy-3-methylglutaryl-CoA synthase \\
\hline YML075C & HMG1 & -6.92 & -7.35 & 6.03 & 6.54 & 3-Hydroxy-3-methylglutaryl-CoA reductase \\
\hline YMR208W & $E R G 12$ & -3.62 & -4.78 & 3.76 & 3.87 & Mevalonate kinase \\
\hline YMR220W & $E R G 8$ & -4.50 & -3.45 & 2.11 & 2.28 & Phosphomevalonate kinase \\
\hline YNR043W & MVD1 & -9.39 & -10.02 & 2.95 & 3.52 & Mevalonate pyrophosphate decarboxylase \\
\hline YPL117C & $\mid D / 1$ & -2.85 & -3.72 & 2.70 & 2.54 & Isopentenyl diphosphate isomerase \\
\hline YJL167W & ERG20 & -6.65 & -5.63 & 3.94 & 2.73 & Farnesyl pyrophosphate synthetase \\
\hline YHR190W & ERG1 & -14.58 & -9.67 & 6.22 & 3.79 & Squalene epoxidase \\
\hline YHR072W & ERG7 & -5.16 & -5.59 & 2.36 & 3.24 & Lanosterol synthase \\
\hline YHR007C & $E R G 11$ & -11.73 & -9.61 & 6.15 & 4.27 & Lanosterol 14-a-demethylase \\
\hline YGR060W & ERG25 & -6.56 & -7.09 & 6.17 & 5.99 & C-4 methyl sterol oxidase \\
\hline YGL001C & ERG26 & -3.79 & -3.71 & 4.95 & 4.28 & C-3 sterol dehydrogenase \\
\hline YML008C & ERG6 & -4.50 & -4.41 & 2.72 & 2.47 & Delta-24-sterol C-methyltransferase \\
\hline YMR202W & $E R G 2$ & -21.42 & -14.46 & 4.95 & 3.73 & C-8 sterol isomerase \\
\hline YLR056W & ERG3 & -8.00 & -9.96 & 4.17 & 4.34 & C-5 sterol desaturase \\
\hline YMR015C & ERG5 & -4.08 & -4.95 & 4.55 & 6.70 & C-22 sterol desaturase \\
\hline
\end{tabular}

Relevant genes for which the MA-R4 xylose/glucose ratio (C1) was lower than two, and the glucose MA-R4/MA-B4 ratio (C4) was higher than two, were selected. The DNA microarray analysis was repeated twice (Values shown in C1-2 and C4-2 are from dye-swap experiments).

together, one can assume that the high expression level of ergosterol-related genes in MA-R4 might increase its ability to grow on glucose under anaerobic conditions and/or promote ethanol tolerance. Although these views are speculative at present, they warrant further study. However, oxygen is required for the biosynthesis of ergosterol, and ergosterol cannot be synthesized under anaerobic conditions [39]. That may mean that a shortage of ergosterol under these conditions induces the ergosterol-related genes without enhancing its synthesis. Oxygen stimulates some ergosterol-related genes such as HMG1 and ERG9 through the transcriptional factor Hap1p [40,41]. BY4947, the host strain of MA-B4, is a diploid of strain S288C, which carries a Ty1 transposon insertion in the HAP1 gene. We confirmed no transposon insertion in the HAP1 gene in IR-2, the host strain for MA-R4 (data not shown). In other words, MA-R4 has wild-type HAP1 unlike MA-B4, which has a mutant allele of HAP1. Therefore, we hypothesized that the higher expression levels of ergosterol-related genes in MA-R4 compared to MA-B4 might be caused by the inactivation of Hap1p in MA-B4. It has been reported that a number of genes encoding enzymes involved in ergosterol biosynthesis are highly expressed in the sake yeast strain Kyokai no. 7 that has wild-type HAP1 [42]. In any case, more detailed analysis is required to clarify the mechanism by which ergosterol-related genes are induced under these conditions.

\section{Expression of genes encoding activities of central carbon} pathways

To obtain information on genes regulated by a carbon source, expression profiles of genes involved in central carbon metabolism pathways were examined. Figure 3 shows the expression of genes related to central carbon metabolism pathways that consist of glycolysis, gluconeogenesis, the pentose phosphate pathway (PPP), and the tricarboxylic acid (TCA) cycle, altogether leading to the production of metabolic energy. Several reaction steps in central carbon metabolism are irreversible, with more than one isozyme being involved in the catalysis of forward and backward reactions. As expected, there are a large number of genes whose expression is altered by the two carbon sources in both MA-R4 and MA-B4 strains (Figure 3). The hexokinase gene $H X K 1$ was expressed more highly with xylose than with glucose, regardless of yeast strain (Figure 3 ). High expression of $H X K 1$ has previously been reported under aerobic and anaerobic xylose growth $[22,25,27]$, and during growth on non-fermentable carbon sources [43]. The expression of the glucokinase gene GLK1 is also regulated by non-fermentable carbon sources [43], and was higher with xylose than with glucose in both strains (Figure 3). The FBP1 gene encoding fructose-1, 6-bisphosphatase 1, the key regulatory enzyme in the gluconeogenesis pathway, was up-regulated during xylose fermentation, irrespective of yeast strain (Figure 3 ). The TDH1 gene, which encodes a glyceraldehyde-3-phosphate 


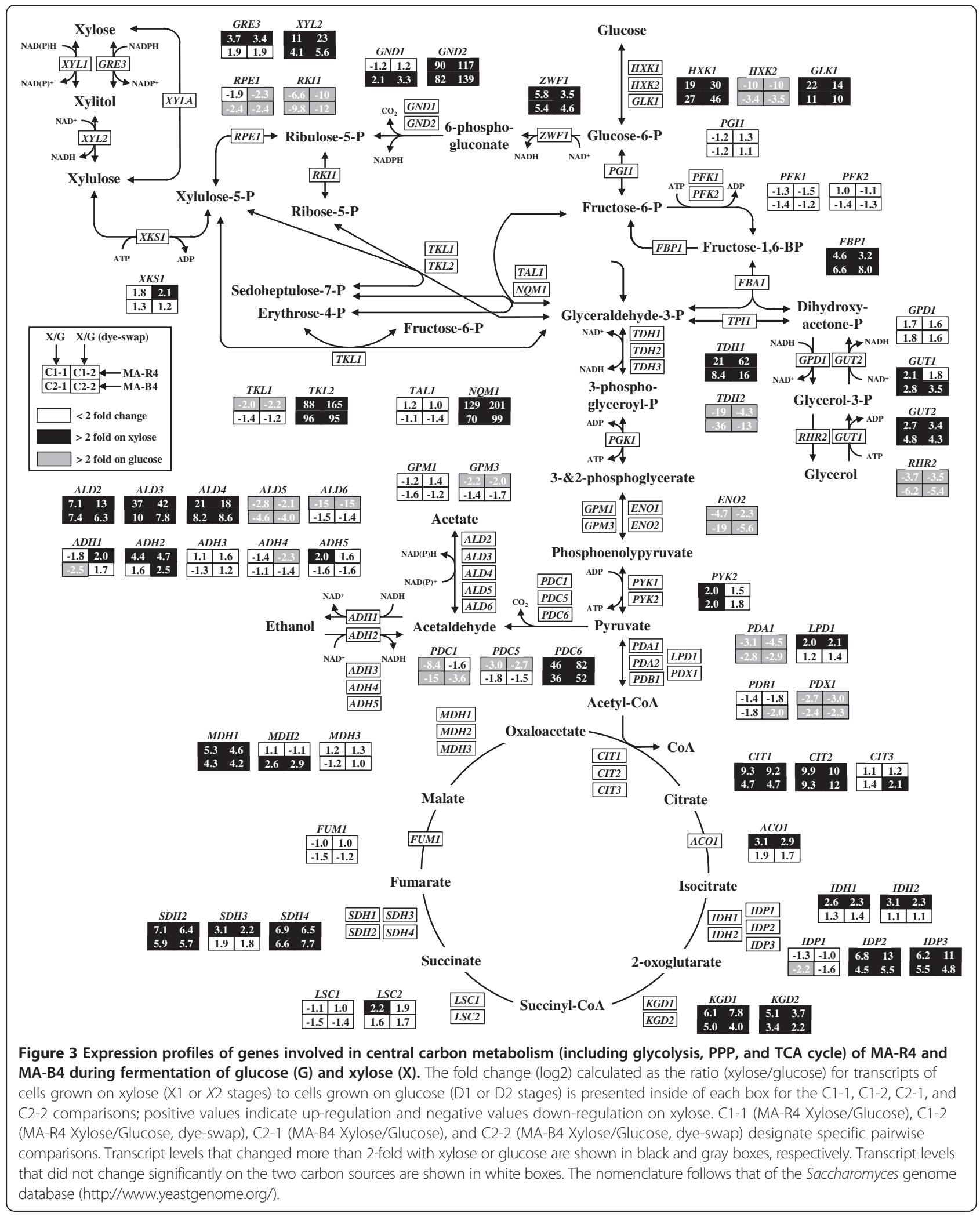

dehydrogenase (GAPDH) isozyme, is primarily expressed during the stationary phase [44] and was up-regulated with xylose (Figure 3). GAPDH activity is also known to be required during gluconeogenesis. In agreement with these results, when grown on xylose compared to growth on glucose, transcripts for the gluconeogenic enzymes 
encoded by ICL1 and PCK1 were induced 2.3- and 3.7-fold in MA-R4 and 2.1- and 2.8-fold in MA-B4, respectively (data not shown). Thus, the several isozymes specific for gluconeogenesis were induced during anaerobic xylose utilization, which is consistent with previous reports $[20,22,25]$. On the other hand, transcripts for several enzymes in the lower half of the glycolytic pathway, including some isozymes encoded by TDH2, GPM3, and ENO2, increased during glucose fermentation (Figure 3).

In this study, the heterologous $X Y L 1$ and $X Y L 2$ genes encoding $\mathrm{XR}$ and $\mathrm{XDH}$ from $S$. stipitis were not included in the $S$. cerevisiae DNA microarrays, but the $S$. cerevisiae genes encoding enzymes with XR (GRE3) [45] and XDH (XYL2) [46] showed increased expression during fermentation with xylose compared to glucose fermentation (Figure 3). In particular, MA-R4 had a high expression level of GRE3 and endogenous XYL2 during fermentation with xylose. In MA-R4, the XKS1 gene encoding XK was expressed at levels about twice as high when xylose was the only sugar as when glucose was the only sugar (Figure 3). Interestingly, XKS1 was more highly expressed in MA$\mathrm{R} 4$ than in MA-B4 under both fermentation conditions (Table 4).

In the oxidative part of the PPP, the ZWF1 and GND2 genes, encoding glucose-6-phosphate dehydrogenase and NADPH-producing 6-phosphogluconate dehydrogenase, respectively, were significantly up-regulated with xylose in MA-R4 and MA-B4 (Figure 3). In particular, GND2 was highly increased by more than 80 -fold in fermentation with xylose compared to glucose. These results support the idea that low carbon flux through glycolysis from the PPP is one of the biggest factors restricting xylose utilization [30]. It is also worth noting that ZWF1 and GND2 are induced during the stress response, perhaps to help replenish NADPH reducing equivalents $[47,48]$. The NQM1 and TKL2 genes, encoding the minor transaldolase and transketolase in the non-oxidative PPP [49], were significantly up-regulated during xylose fermentation in both strains, and their expression levels were increased more than 70-fold and 88-fold, respectively (Figure 3). These results are consistent with our previous finding that transcription of NQM1 in MA-R4 is elevated more than 4-fold in xylose-containing medium compared with that in glucose-containing medium by real-time PCR [49]. Therefore, these results strongly support the view that NQM1 may be involved in the xylose metabolic pathway or in an unknown xylose utilizing pathway via the nonoxidative PPP [49]. Meanwhile, it was unexpected that in MA-R4 and MA-B4, the transcript levels of TKL2 would be greatly elevated in the xylose-containing medium compared with glucose-containing medium (Figure 3 and Table 5), because our previous studies showed that the expression of TKL2 is very low in MA-R4 regardless of the culture conditions [49]. TKL2 is induced in response to heat shock in an Msn2/4p-dependent manner [50], and several target genes of Msn2/4p, including TKL2, were greatly up-regulated with xylose (Table 5). Taking these results together, it is tempting to speculate that the induction of TKL2 was increased through Msn2/4p-mediated stress responses rather than in response to xylose as the sole carbon source. On the other hand, the transcription of TAL1 and TKL1, the major transaldolase

Table 4 Expression levels of genes significantly increased in MA-R4 relative to MA-B4

\begin{tabular}{|c|c|c|c|c|c|c|}
\hline \multirow[t]{2}{*}{ ORF } & \multirow[t]{2}{*}{ Gene } & \multicolumn{2}{|c|}{$\begin{array}{c}\text { Xylose } \\
\text { MA-R4/MA-B4 (C3) }\end{array}$} & \multicolumn{2}{|c|}{$\begin{array}{c}\text { Glucose } \\
\text { MA-R4/MA-B4 (C4) }\end{array}$} & \multirow[t]{2}{*}{ Description } \\
\hline & & (C3-1) & $(\mathrm{C} 3-2)$ & (C4-1) & $(C 4-2)$ & \\
\hline \multicolumn{7}{|c|}{ Xylose metabolism } \\
\hline YGR194C & XKS1 & 7.23 & 6.13 & 11.97 & 9.20 & Xylulokinase \\
\hline \multicolumn{7}{|c|}{ Hexose transporters } \\
\hline YMR011W & HXT2 & 41.40 & 26.68 & 2.20 & 2.38 & High-affinity glucose transporter \\
\hline YDR345C & HXT8 & 7.17 & 16.25 & 4.10 & 5.35 & $\begin{array}{l}\text { Protein of unknown function with similarity to hexose transporter } \\
\text { family members }\end{array}$ \\
\hline \multicolumn{7}{|c|}{ Other transporters } \\
\hline YCR098C & GlT1 & 13.32 & 8.90 & 2.53 & 2.28 & $\begin{array}{l}\text { Plasma membrane permease, mediates uptake of } \\
\text { glycerophosphoinositol and glycerophosphocholine }\end{array}$ \\
\hline YLR237W & THI7 & 2.33 & 2.97 & 2.05 & 2.14 & Plasma membrane transporter responsible for the uptake of thiamine \\
\hline YKR093W & PTR2 & 2.32 & 2.69 & 8.30 & 8.87 & Integral membrane peptide transporter \\
\hline \multicolumn{7}{|c|}{ ATP synthesis } \\
\hline YBR085W & AAC3 & 3.42 & 3.08 & 4.89 & 3.68 & Mitochondrial inner membrane ADP/ATP translocator \\
\hline Q0080 & ATP8 & 4.25 & 5.61 & 3.65 & 4.33 & $\begin{array}{l}\text { Subunit } 8 \text { of the F0 sector of mitochondrial inner membrane } \\
\text { F1-F0 ATP synthase }\end{array}$ \\
\hline
\end{tabular}


Table 5 Expression levels of known Msn2/4p-dependent genes

\begin{tabular}{|c|c|c|c|c|c|c|}
\hline \multirow[t]{2}{*}{ ORF } & \multirow[t]{2}{*}{ Gene } & \multicolumn{2}{|c|}{ MA-R4 xylose/glucose (C1) } & \multicolumn{2}{|c|}{ MA-B4 xylose/glucose (C2) } & \multirow[t]{2}{*}{ Description } \\
\hline & & (C1-1) & $(\mathrm{C} 1-2)$ & $(\mathrm{C} 2-1)$ & $(\mathrm{C} 2-2)$ & \\
\hline YER150W & SPII & 126.64 & 199.67 & 48.44 & 67.29 & GPI-anchored cell wall protein \\
\hline YOL052C-A & DDR2 & 105.36 & 135.30 & 99.99 & 232.51 & Multi-stress response protein \\
\hline YBR117C & $T K L 2$ & 87.83 & 164.53 & 95.81 & 94.69 & Transketolase \\
\hline YGR088W & CTT1 & 38.28 & 49.52 & 17.11 & 21.33 & Catalase T \\
\hline YMR169C & ALD3 & 37.09 & 42.34 & 10.28 & 7.78 & Aldehyde dehydrogenase \\
\hline YBL075C & SSA3 & 24.17 & 17.42 & 12.94 & 14.98 & Chaperone protein \\
\hline YLR258W & GSY2 & 11.84 & 16.29 & 5.01 & 6.14 & Glycogen synthase \\
\hline YDR171W & HSP42 & 10.65 & 9.66 & 5.25 & 5.53 & Heat shock protein \\
\hline YDR258C & HSP78 & 10.11 & 7.85 & 5.36 & 4.66 & Heat shock protein \\
\hline YMR170C & ALD2 & 7.08 & 12.90 & 7.38 & 6.28 & Aldehyde dehydrogenase \\
\hline YLL026W & HSP104 & 6.89 & 7.95 & 6.11 & 6.61 & Heat shock protein \\
\hline YDR074W & TPS2 & 5.27 & 4.61 & 4.55 & 4.72 & Trehalose-6-phosphate phosphatase \\
\hline YBR126C & TPS1 & 4.95 & 6.86 & 4.75 & 7.17 & Trehalose-6-phosphate synthase \\
\hline YHR008C & SOD2 & 2.48 & 2.14 & 2.65 & 2.29 & Superoxide dismutase \\
\hline
\end{tabular}

Relevant genes for which the MA-R4 xylose/glucose ratio (C1) and the MA-B4 xylose/glucose ratio (C2) were higher than two were selected. The DNA microarray analysis was repeated twice (Values shown in C1-2 and C2-2 are from dye-swap experiments).

and transketolase genes, was relatively unchanged between xylose-grown and glucose-grown cells (Figure 3). Other genes encoding enzymes of the non-oxidative PPP, ribulose-5-phosphate 3-epimerase (RPE1) and ribose5-phosphate ketol-isomerase (RKI1), were expressed at lower levels in yeast cells cultivated on xylose (Figure 3).

Several genes encoding TCA cycle enzymes increased in xylose-utilizing yeast strains, and many of them (e.g. CIT1, CIT2, IDP2, IDP3, KGD1, KGD2, SDH2, SDH4, and $M D H 1$ ) were induced to a greater extent in MA-R4 compared with MA-B4 (Figure 3). There were some exceptions with regard to the expression of the genes; $M D H 2$, which encodes cytosolic malate dehydrogenase, was expressed at a relatively high level only in MA-B4, and the expressions of the mitochondrial $\mathrm{NADP}^{+}$-dependent isocitrate dehydrogenase gene IDP1, the succinyl-CoA ligase gene $L S C 1$, and the fumarase gene FUM1 were slightly lower with xylose in both strains. In addition to the fact that TCA cycle genes were expressed more strongly in xylose-utilizing cells than in glucose-utilizing cells, genes involved in respiration (e.g. COR1, COX1, COX5B, QCR8, CYC3, and CYC7) were up-regulated during xylose fermentation (Table 6). Thus, the expression of genes encoding the TCA cycle and respiration enzymes increased significantly when strains were cultivated anaerobically on xylose, indicating that $S$. cerevisiae engineered for xylose metabolism does not exhibit a fermentative response to the sugar even under anaerobic conditions. Induced transcription of genes encoding enzymes of the TCA cycle and respiration during xylose metabolism has also been observed in previous studies [22,25,27]. Respiratory conditions increase reactive oxygen species (ROS), so that genes involved in adaptation to ROS, such as MGA2 that is implicated in DNA repair [51], should also increase. In the present study MGA2 in both strains increased by more than 3 -fold in xylose-containing medium compared with glucose-containing medium (data not shown), indicating that xylose induces adaptation to oxidative stress. It should be also noted that in MA-B4, transcript levels of HAP4, encoding a transcriptional activator and global regulator of respiratory gene expression [52], were more than 6.7-fold higher with xylose than with glucose, but did not change significantly with respect to carbon sources in MA-R4 (data not shown). It is also worth mentioning that stress responses induce the expression of genes that are implicated in respiration, including CIT1 and CYC7. Increasing the levels of these gene products may promote ATP synthesis by utilizing existing respiration components. Alternatively, the induction of factors that promote cytochrome $c$ and ubiquinone synthesis may play a role in the defense against oxidative stress rather than in ATP generation [53].

In the alcohol catabolism and by-product pathways, several genes were changed significantly. The major isozymes of the pyruvate decarboxylase gene $P D C 1$ were up-regulated with glucose, while PDC6, encoding the minor isoform of pyruvate decarboxylase, was highly up-regulated with xylose in both MA-R4 and MA-B4 (Figure 3). Interestingly, PDC6 is strongly induced under nutrient-limited conditions, especially during sulfur deficiency [54]. Transcripts of $A D H 2$, which encodes glucoserepressible alcohol dehydrogenase 2 , increased with xylose, especially in MA-R4 (Figure 3). In general, $A D H 2$ as well as $H X K 1$ are repressed by glucose. The genes encoding the 
Table 6 Expression levels of genes with significantly changed in xylose metabolism relative to glucose metabolism

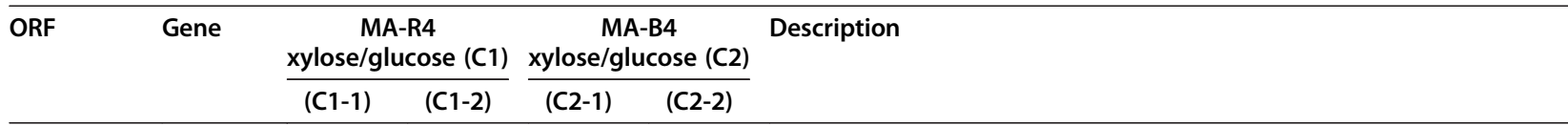

\begin{tabular}{|c|c|c|c|c|c|c|}
\hline \multicolumn{7}{|c|}{ Respiratory metabolism } \\
\hline YBL045C & COR1 & 2.37 & 2.73 & 3.00 & 2.75 & $\begin{array}{l}\text { Core subunit of the ubiquinol-cytochrome } c \text { reductase complex (bc1 } \\
\text { complex) }\end{array}$ \\
\hline Q0045 & $\operatorname{cox} 1$ & 2.17 & 2.55 & 2.25 & 2.50 & Subunit I of cytochrome c oxidase \\
\hline YIL111W & COX5B & 7.20 & 11.74 & 2.87 & 2.62 & Subunit Vb of cytochrome c oxidase \\
\hline YMR256C & $\operatorname{cox} 7$ & 2.06 & 2.38 & 3.87 & 3.95 & Subunit VII of cytochrome $c$ oxidase \\
\hline YGL191W & $\operatorname{cox} 13$ & 2.15 & 2.89 & 4.21 & 5.33 & Subunit Vla of cytochrome $c$ oxidase \\
\hline YDR231C & $\operatorname{cox} 20$ & 4.97 & 4.39 & 4.61 & 4.94 & Mitochondrial inner membrane protein \\
\hline YJL166W & QCR8 & 2.66 & 3.36 & 3.87 & 5.50 & Subunit 8 of ubiquinol cytochrome $c$ reductase complex \\
\hline YAL039C & CYC3 & 2.31 & 2.11 & 5.63 & 6.08 & Cytochrome $c$ heme lyase (holocytochrome $c$ synthase) \\
\hline YEL039C & CYC7 & 7.40 & 8.71 & 31.54 & 37.06 & Cytochrome $\mathrm{c}$ isoform 2 \\
\hline YPL159C & PET20 & 2.54 & 2.98 & 2.13 & 2.80 & Mitochondrial protein \\
\hline YLR154W-C & TAR1 & 2.25 & 4.70 & 2.32 & 4.56 & Mitochondrial protein \\
\hline \multicolumn{7}{|c|}{ Hexose transporters } \\
\hline YHR094C & HXT1 & -30.45 & -21.51 & -56.36 & -46.31 & Low-affinity glucose transporter \\
\hline YDR345C & HXT3 & -54.60 & -20.87 & -83.61 & -32.66 & Low-affinity glucose transporter \\
\hline YHR096C & HXT5 & 22.20 & 48.69 & 22.78 & 44.86 & Hexose transporter with moderate affinity for glucose \\
\hline \multicolumn{7}{|c|}{ Galactose metabolism } \\
\hline YBR020W & GAL1 & 19.10 & 32.47 & 3.71 & 5.48 & Galactokinase \\
\hline YDR009W & GAL3 & 4.20 & 4.91 & 6.88 & 9.85 & $\begin{array}{l}\text { Transcriptional regulator involved in activation of the GAL genes in response } \\
\text { to galactose }\end{array}$ \\
\hline YPL248C & GAL4 & 3.44 & 4.04 & 9.38 & 7.75 & $\begin{array}{l}\text { DNA-binding transcription factor required for the activation of the GAL genes } \\
\text { in response to galactose }\end{array}$ \\
\hline YBR018C & GAL7 & 7.05 & 13.98 & 5.29 & 10.70 & Galactose-1-phosphate uridyl transferase \\
\hline YBR019C & GAL10 & 45.93 & 203.38 & 16.32 & 14.96 & UDP-glucose-4-epimerase \\
\hline
\end{tabular}

Spore wall metabolism

$\begin{array}{llccccl}\text { YHR139C } & \text { SPS100 } & 53.16 & 93.57 & 12.99 & 18.00 & \text { Protein required for spore wall maturation } \\ \text { YDR403W } & \text { DIT1 } & 4.77 & 8.66 & 4.68 & 6.11 & \text { Sporulation-specific enzyme required for spore wall maturation } \\ \text { YDR402C } & \text { DIT2 } & 3.86 & 2.59 & 6.18 & 3.33 & \text { N-formyltyrosine oxidase } \\ \text { YGR032W } & \text { GSC2 } & 10.25 & 15.12 & 9.91 & 17.89 & \text { Catalytic subunit of 1,3-beta-glucan synthase } \\ \text { YMR306W } & \text { FKS3 } & 8.57 & 9.05 & 10.66 & 7.54 & \text { Protein involved in spore wall assembly } \\ \text { YDL239C } & \text { ADY3 } & 2.89 & 3.82 & 2.31 & 2.26 & \text { Protein required for spore wall formation }\end{array}$

\begin{tabular}{lllll}
\hline Ammonia secretion & & \\
YNR002C ATO2 & $8.78 \quad 36.19 \quad 9.57 \quad 13.26 \quad$ Putative transmembrane protein involved in export of ammonia
\end{tabular}

\begin{tabular}{|c|c|c|c|c|c|c|}
\hline YNR002C & ATO2 & 8.78 & 36.19 & 9.57 & 13.26 & Putative transmembrane protein involved in export of ammonia \\
\hline \multicolumn{7}{|c|}{ Trehalose metabolism } \\
\hline YBR126C & TPS1 & 4.95 & 6.86 & 4.75 & 7.17 & Synthase subunit of trehalose-6-P synthase/phosphatase complex \\
\hline YML100W & TSL 1 & 17.88 & 18.11 & 8.01 & 6.82 & Large subunit of trehalose 6-phosphate synthase/phosphatase complex \\
\hline
\end{tabular}

Relevant genes for which the MA-R4 xylose/glucose ratio (C1) was lower than two, and the MA-B4 xylose/glucose ratio (C2) was higher than two, were selected. The DNA microarray analysis was repeated twice (Values shown in C1-2 and C2-2 are from dye-swap experiments).

transcription factors $A D R 1$ and $C A T 8$, which regulate the expression of $A D H 2$ [55,56], had more than 10-fold higher transcript levels with xylose than with glucose in both strains (data not shown). Another ethanol oxidation enzyme, acetyl-CoA synthetase encoded by ACS1, is also regulated by Adr1p and Cat8p [57], but its expression did not change significantly between the two carbon sources (data not shown). Among the $A L D$ genes involved in acetate formation, isoenzymes of cytosolic aldehyde dehydrogenases, encoded by $A L D 2$ and $A L D 3$, 
and the mitochondrial aldehyde dehydrogenase gene $A L D 4$, were up-regulated with xylose (Figure 3), suggesting that acetaldehyde was utilized for growth instead of ethanol production during xylose fermentation. In contrast, the expression of $A L D 5$, encoding another mitochondrial aldehyde dehydrogenase, was lower with xylose (Figure 3). Meanwhile, in only MA-R4, ALD6, which is responsible for the cytoplasmic synthesis of acetate from acetaldehyde, had its lowest abundance with xylose (Figure 3). The expression of glucose-repressible $A C H 1$, encoding a mitochondrial acetyl-CoA hydrolase [58], had more than 9-fold higher transcription with xylose than with glucose in both strains (data not shown). The observed higher expression of genes involved in acetaldehyde and acetyl-CoA metabolism during xylose fermentation is consistent with a previous report [25] suggesting that the mitochondrial acetate concentration is perhaps elevated during growth on xylose compared with growth on glucose. In the glycerol catabolism pathway, the expression of genes GUT1 and GUT2, encoding glycerol kinase and mitochondrial glycerol 3-phosphate dehydrogenase, respectively, increased during xylose fermentation (Figure 3). Conversely, the glycerolproducing gene RHR2, encoding glycerol 1-phosphatase, had a lower expression level with xylose than with glucose (Figure 3). The expression of GUT1 and GUT2 together with $H X K 1, G L K 1, F B P 1$, and PCK1 is known to increase during growth on non-fermentable carbon sources $[43,59,60]$. Combining these results, we can conclude that xylose-utilizing $S$. cerevisiae recognizes xylose as a non-fermentable carbon source.

\section{Expression of sugar transporter genes and galactose metabolism genes}

Although hexose transporters (encoded by the HXT genes) in $S$. cerevisiae transport not only glucose but also xylose, these transporters have less specificity and lower affinity for xylose than for glucose [61]. We confirmed that transcript levels of $H X T 1$ and $H X T 3$ encoding the low-affinity glucose transporters were highly induced in the strains grown on glucose (Table 6), which is consistent with a previous finding that the expression of $H X T 1$ and $H X T 3$ is induced by high glucose concentrations [62]. In contrast, the HXT5 gene, encoding a functional hexose transporter that has moderate affinity for glucose (40 mM) [63], had higher expression in fermentation with xylose compared with glucose (Table 6), suggesting that glucose represses the transcription of HXT5. Transcription of HXT5 is induced in the presence of non-fermentable carbon sources [63] and during carbon source limitation [54]. Therefore, these results support the idea that xylose is sensed as a non-fermentable carbon source, and the expression of HXT5 might be induced under conditions of energy and carbon source limitation.
In xylose-containing medium, there was also an increase in the expression of a gene implicated as being a hexose uptake sensor (SNF3), which showed more than 3- and 5-fold higher transcription in MA-R4 and MA-B4, respectively (data not shown). HXT2, encoding a lowaffinity glucose transporter, and $H X T 8$, encoding a glucose transporter-like protein, had higher transcript levels in MA-R4 than in MA-B4 (Table 4). The expression of these two genes is induced by low levels of glucose and repressed by high levels of glucose [64].

Together with some hexose transport genes, the gene encoding galactose permease (GAL2) was up-regulated by more than 7.6-fold with xylose in both MA-R4 and MA-B4 (data not shown). GAL2 has been shown to transport xylose as well as galactose and glucose [61], although overexpressing GAL2 does not improve xylose growth [65]. In addition, GAL1, GAL3, GAL4, GAL7, and GAL10 in galactose metabolism were up-regulated by xylose (Table 6). The activation of galactose metabolismrelated genes is induced by the dominant positive regulator coding gene $G A L 3$, and the higher expression level of GAL3 (Table 6) probably resulted in the strong upregulation of $G A L$ genes $[23,66]$. Our finding that the expression of GAL genes was higher when xylose was the only sugar than when glucose was the only sugar is consistent with other published DNA microarray data $[23,65,66]$. In addition, the MIG1 gene, encoding a transcription factor involved in glucose repression, also regulates genes involved in galactose metabolism [20]. In the presence of glucose, MIG1 causes repression of the transcription of genes implicated in galactose metabolism [67]. It is worth mentioning that transcription of MIG1 was induced more than 3.7-fold in MA-R4 when grown on glucose compared to xylose, although the expression of MIG1 was comparable in the glucoseand xylose-grown MA-B4 (data not shown). Thus, the results suggest that in MA-R4, induction of galactose metabolism-related genes by xylose is partially regulated by Mig1p.

\section{Starvation response during xylose fermentation}

The absence of a nitrogen source combined with the presence of a non-fermentable carbon source leads diploid cells of $S$. cerevisiae to enter the developmental pathway of meiosis and sporulation [68]. In both xylosefermenting diploid strains of $S$. cerevisiae, MA-R4 and MA-B4, several genes involved in spore wall metabolism (SPS100, DIT1, DIT2, GSC2, FKS3, and ADY3) showed an increase in expression during xylose fermentation (Table 6). SPS100, which contributes to spore wall maturation [69], was dramatically induced in the presence of xylose, especially in MA-R4 (Table 6). DIT1 and DIT2, which encode enzymes mediating spore wall assembly [70]; GSC2 and FKS3, which are involved in the 
formation of the inner ( $\beta$-glucan) layer of the spore wall [71]; and $A D Y 3$, which encodes a protein required for spore wall formation [72], were also up-regulated in cells grown on xylose (Table 6).

In addition to the genes involved in spore wall metabolism, the expression of ATO2 encoding a putative ammonium transporter had higher transcript levels with xylose in the two recombinant yeast strains (Table 6). Ato2p, together with Ato1p and Ato3p, are all members of the YaaH family of proteins with six transmembrane domains that has been proposed to be involved in the export of ammonia, and their genes were strongly expressed during the alkali phase of colony growth that is accompanied by increased ammonia production [73]. The ammonia release is a starvation signal that directs the growth of colonies away from neighboring colonies and toward more nutrient-rich areas on the plate $[24,73]$. However, the transcript levels of another putative ammonium transporter gene, ATO3, did not change significantly with respect to the carbon source in MA-R4 and MA-B4 (data not shown). In addition, ATO1 was not detected in this study.

\section{Expression of Msn2/4p-mediated genes}

Msn2p and Msn4p (Msn2/4p) are functionally redundant transcription factors that regulate the general stress response of $S$. cerevisiae $[74,75]$. Each factor binds to a heat shock element (HSE) or stress response element (STRE) found in the promoters of many stress response genes. The known target genes of Msn2/4p were remarkably up-regulated with xylose in both MA-R4 and MA-B4 (Table 5). Genes up-regulated in the presence of xylose included the following large set of stress-responsive genes: SPI1, which encodes a member of the glycosylphosphatidylinositol (GPI)-anchored cell wall protein family that protects the yeast cell from damage caused by weak acids [76]; $D D R 2$, which encodes a multi-stress response protein and is transcriptionally activated by a variety of xenobiotic agents and environmental or physiological stresses [77]; carbohydrate metabolism-related genes (TKL2, ALD2, ALD3, GSY2, TPS1, and TPS2); oxidative stress defense-related genes (CTT1 and SOD2); and protein folding chaperones (SSA3, HSP42, HSP78, and HSP104). Among these stress-induced genes, SPI1 was highly increased by more than 126-fold in MA-R4 when fermenting with xylose compared to glucose (Table 5). $D D R 2$ was also significantly up-regulated during xylose fermentation in both MA-R4 and MA-B4, and its transcript levels were induced more than 105-fold and 99-fold, respectively (Table 5). In agreement with the elevated expression levels of a large number of Msn2/4p gene targets in the xylose culture, the transcription of MSN4 (data not shown) was induced during xylose fermentation more than 2.7- and 4.4-fold in MA-R4 and MA-B4, respectively. However, the levels of MSN2 transcripts were comparable in xylose and glucose cultures (data not shown). As with many other Msn2/4p-mediated genes containing STREs, the expression of the trehalose synthase genes, TPS1, TPS2, and TSL1, was also induced in the presence of xylose (Table 6). It has been shown that transcripts of these three genes are coregulated and increase under various stress conditions, including nutrient starvation $[78,79]$, and that trehalose serve as a stress protectant in many organisms.

At present, the molecular mechanism of the regulation of stress-responsive genes in response to xylose remains elusive, but the results of the present study strongly support the view that genes that respond to starvation for nutrients, such as carbon and nitrogen sources, and oxidative stress are induced during xylose fermentation. This hypothesis was confirmed by the finding that several genes involved in spore wall metabolism (SPS100, DIT1, DIT2, GSC2, FKS3, and ADY3), the putative ammonium transporter gene encoded by $A T O 2$, and the minor isoform of pyruvate decarboxylase gene $P D C 6$, as well as a number of TCA cycle and respiration genes, increased in expression when fermenting with xylose (Table 6 and Figure 3). In our previous paper [30], we also showed that carbon and energy starvation conditions are normal in MA-R4 during fermentation with xylose. Therefore, it is also tempting to speculate that recombinant xylose-metabolizing $S$. cerevisiae strains respond to xylose as though they were experiencing carbon and energy starvation, leading to the activation of Msn2/4p-dependent transcription.

\section{Expression of genes increased in MA-R4 relative to MA-B4}

Recombinant industrial $S$. cerevisiae strains such as MA-R4 have some special features for ethanol production, including high ethanol productivity, high tolerance to ethanol, and tolerance to inhibitory compounds, compared to recombinant laboratory strains such as MA-B4 [3,31]. From gene expression profiles, we obtained further evidence for these special features and other abilities of MA-R4. As mentioned above, two hexose transport genes, HXT2 and HXT8, as well as the XKS1 gene encoding xylulokinase (XK) in xylose metabolism had higher transcript levels in MA-R4 than in MA-B4, irrespective of carbon source (Table 4). The higher expression levels of XKS1 found in MA-R4 (Table 4) agreed well with the higher XK activities (more than doubled) in the cell extracts (data not shown). Some genes encoding membrane transporters other than sugar transporters (GIT1, THI7, and PTR2) were also more highly expressed in MA-R4 than in MA-B4 (Table 4). GIT1 encodes a permease involved in the uptake of glycerophosphoinositol (GroPIns) and glycerophosphocholine (GroPCho) as sources of the nutrients inositol and phosphate [80,81]. 
Inositol and phosphate are important nutrients for all eukaryotic cells, including S. cerevisiae; inositol serves as an important component of the structural phosphatidylinositol class of lipids, and phosphate is required to make two of the most important organic macromolecules, DNA and ATP. It is known that much of the GroPIns produced are excreted into the medium, and external GroPIns can be transported into yeast cells in times of nutritional stress (inositol or phosphate limitation) via Git1p permease [80]. Therefore, it is reasonable to hypothesize that during fermentation, MAR4 can transport and utilize inositol and/or phosphate more efficiently compared with MA-B4 in response to these nutritional stresses. Meanwhile, THI7 encodes a transporter responsible for the uptake of thiamine [82]. Thiamine is an important co-factor of pyruvate decarboxylase for ethanol production in yeast cells. Therefore, one can assume that the level of thiamine in MA-R4 might be low due to the consumption of thiamine in yeast cells as a co-factor for pyruvate decarboxylase in ethanol fermentation. PTR2 encodes an integral membrane peptide transporter that mediates the transport of di- and tri-peptides [83]. Utilization of di/tripeptides as nitrogen and carbon sources and for protein synthesis is an important cellular process in all organisms, and di/tri-peptides regulate a variety of cellular processes such as gene transcription, protein translation, and enzyme activity. In yeasts, peptide transport is up-regulated in growth media containing poor nitrogen sources. Interestingly, GIT1 showed high expression levels during xylose fermentation, whereas PTR2 had high expression levels during glucose fermentation (Table 4). Taken together, the uptake of GroPIns, GroPCho, thiamine, and di/tripeptides is important for the higher rates of anaerobic growth and sugar consumption, and the higher fermentation ability, of MA-R4 as a recombinant industrial yeast. It would also be of interest to examine the intracellular levels of these substrates in MA-R4 and MA-B4 during fermentation.

The ADP/ATP translocator gene AAC3 [84] and ATP synthase gene ATP8 [85], both of which are regulated at the mitochondrial inner membrane to generate ATP from ADP, were up-regulated in MA-R4 regardless of carbon source (Table 4), implying that MA-R4 gains more energy for the cell through ATP synthesis than MA-B4. It has been suggested that the rate of ATP formation is the primary limiting factor for anaerobic growth on xylose alone [23]. Therefore, lower ATP levels in MA-B4 compared with MA-R4 may be responsible for the lower efficiency of anaerobic growth and fermentation of MA-B4. Interestingly, the deletion of ATP8, like deletions in many genes necessary for the function or maintenance of mitochondria, leads to a "petite" phenotype that is slow-growing and unable to survive on nonfermentable carbon sources [86]. Thus, genes involved in ATP synthesis as well as genes encoding a variety of membrane transporters were expressed at higher levels in MA-R4 than in MA-B4 regardless of the culture conditions used in this study.

\section{Conclusions}

The results of this study using genome-wide gene expression analysis strongly support the conclusion that MA-R4 acquires more energy and nutrients from its higher fermentation ability via the uptake of different compounds and the synthesis of ATP compared to MA-B4, and that high expression levels of ergosterolrelated genes in MA-R4 during glucose fermentation may increase its ability to grow on glucose under anaerobic conditions and/or its ethanol tolerance. This study has further demonstrated that xylose-utilizing $S$. cerevisiae senses xylose as a non-fermentable carbon source, which then induces a starvation response and increases ROS, leading to an increase in the expression of many genes involved in stress. These views are still speculative, and none of the above assumptions has yet been fully proven. However, these ideas provide us with a preliminary basis for understanding the molecular events underlying the response to xylose or glucose, and the differences between industrial and laboratory strains during fermentation.

\section{Methods}

\section{Yeast strains and media}

The recombinant xylose-utilizing $S$. cerevisiae strains MAR4 and MA-B4 were used in this study. MA-R4, derived from the industrial diploid and flocculent yeast strain IR-2, was genetically engineered with the chromosomeintegrated XYL1 and XYL2 genes that encode XR and $\mathrm{XDH}$ from $S$. stipitis, along with the endogenous XKS1 gene that encodes XK under the control of the PGK promoter $[31,87]$. S. cerevisiae laboratory strain BY4947 (diploid of S288C, MATa/a SUC2/SUC2 mal/mal mel/ mel gal2/gal2 CUP1/CUP1 flo1/flo1 flo8-1/flo8-1 SSD1$v 1 / S S D 1-v 1)$, which was obtained from the Yeast Genetic Resource Center (YGRC, Osaka University, Osaka, Japan), was another recipient yeast strain for the expression of $X Y L 1, X Y L 2$, and XKS1 genes. For the construction of strains MA-R4 and MA-B4, plasmid pAUR-XKXDHXR [88] was digested with the restriction enzyme BsiWI and chromosomally integrated into the aur1 locus of IR-2 and BY4947, respectively. MA-R4 and MA-B4 were maintained by selective growth on yeast peptone (YP) medium (10 g/L yeast extract and $20 \mathrm{~g} / \mathrm{L}$ peptone) supplemented with $20 \mathrm{~g} / \mathrm{L}$ glucose in the presence of $0.5 \mathrm{mg} / \mathrm{L}$ aureobasidin A (Takara Bio, Kyoto, Japan). Glucose (40 g/L) was added to YP medium to produce YPD medium. Xylose $(40 \mathrm{~g} / \mathrm{L})$ was added to YP medium to produce YPX 
medium. The YPD and YPX media were used as the anaerobic fermentation media in this study.

\section{Fermentation}

For anaerobic batch fermentation, MA-R4 and MA-B4 were first cultivated aerobically in $5 \mathrm{~mL}$ YP medium supplemented with $20 \mathrm{~g} / \mathrm{L}$ glucose and $0.5 \mathrm{mg} / \mathrm{L}$ aureobasidin $\mathrm{A}$ for $36 \mathrm{~h}$ at $30^{\circ} \mathrm{C}$. The resulting cultures were centrifuged at $6000 \times g$ for $5 \mathrm{~min}$ at $4^{\circ} \mathrm{C}$, and the pelleted cells were washed and resuspended in distilled water. The washed cells were inoculated into $20 \mathrm{~mL}$ fermentation medium (YPD and YPX) in which aureobasidin A was not included. For all fermentation media, the initial cell density was adjusted to approximately $2.34 \mathrm{~g}$ (dry cell weight $(\mathrm{DCW}))$ per liter. Anaerobic batch fermentations were performed at $30^{\circ} \mathrm{C}$ in $50-\mathrm{mL}$ sterilized closed bottles with magnetic stirring as described previously $[31,87,88]$. Samples $(0.3 \mathrm{~mL})$ of fermentation broth (YPD and YPX) were taken at specified intervals and diluted 4-fold with $8 \mathrm{mM} \mathrm{H}_{2} \mathrm{SO}_{4}$. These diluted samples were stored at $-30^{\circ} \mathrm{C}$ for high-performance liquid chromatography (HPLC) analysis of substrates and fermentation products. All experiments were performed in triplicate.

\section{Quantification of biomass, substrates, and fermentation products}

DCW was determined using a UV-2450 spectrophotometer (Shimadzu, Kyoto, Japan) to measure the absorbance of the samples at $600 \mathrm{~nm}$, as described previously [88]. The maximum specific production rates of ethanol and consumption rates of glucose and xylose were calculated as the slope in linear regression of metabolite concentration divided by DCW vs. time [89]. Concentrations of glucose, xylose, ethanol, xylitol, glycerol, and acetic acid were determined with an HPLC apparatus (Jasco, Tokyo, Japan) equipped with a refractive index detector (RI-2031Plus; Jasco) using an Aminex HPX-87H (Bio-Rad Laboratories, Hercules, CA, USA) and Cation $\mathrm{H}$ Refill Guard (Bio-Rad) column. The HPLC apparatus was operated at $65^{\circ} \mathrm{C}$, with $5 \mathrm{mM} \mathrm{H}_{2} \mathrm{SO}_{4}$ as the mobile phase, a flow rate of $0.6 \mathrm{~mL} / \mathrm{min}$, and an injection volume of $20 \mu \mathrm{L}$.

\section{Extraction of RNA}

Yeast cells grown as described above were harvested for transcriptional analysis at times indicated in the Results and Discussion section above. Duplicate samples (approximately $6.44 \mathrm{~g} / \mathrm{L} \mathrm{DCW}$ ) were collected at each time point (all four time points). Total RNA was isolated using the FastRNA Pro Red Kit (Q-BIOgene, Irvine, CA, USA), according to the manufacturer's protocols. RNA was further purified using the RNeasy Mini Kit (Qiagen, Hilden, Germany). RNA quality and concentration were measured using an Agilent 2100 Bioanalyzer (Agilent
Technologies, Palo Alto, CA, USA) and NanoDrop ND1000 (Thermo Fisher Scientific, Waltham, MA, USA), respectively.

\section{DNA microarray analysis and data processing}

DNA microarray analysis was performed using the 3DGene Yeast Oligo Chip 6 k (Toray Industries Inc., Tokyo, Japan/DNA Chip Research, Inc., Yokohama, Japan) as described previously [90-92]. Using total RNA isolated as described above, the amplification and preparation of amino allyl RNA (aRNA) and the labeling of aRNA with the fluorescence dyes Cy3 and Cy5 were carried out with the Amino Allyl MessageAMP II aRNA Amplification Kit (Applied Biosystems, CA, USA). The Cy3- or Cy5labeled aRNA pools and hybridization buffer containing micro beads were mixed on the 3D-Gene Yeast Oligo Chip $6 \mathrm{k}$ for $16 \mathrm{~h}$ at $37^{\circ} \mathrm{C}$. This chip has 3-dimensions that is constructed with a well as the space between the probes and cylinder-stems with 30-mer oligonucleotide probes on the top for efficient hybridization of the Cy3or Cy5-labeled aRNAs and the probes, and contains all 5795 yeast genes registered in the Saccharomyces Genome Database (SGD). The hybridization and wash steps were performed following the supplier's protocols. The hybridized DNA chip was scanned using ScanArray Express HT (PerkinElmer, Waltham, MA, USA). The normalization of the fluorescence intensities of each probe between Cy3 and Cy5 was achieved by the intensity dependent (LOWESS) methods [93]. The cutoff values were defined by the intensity of the background average plus 2SD. Data processing, including hierarchical cluster analysis, was performed using GeneSpringGX10 software (Agilent Technologies). We further used a dye-swap experiment (also called color flip experiment) to show that the dye used for labeling does not cause any bias in allele frequency measurement.

\section{Abbreviations \\ CoA: Coenzyme A; DCW: Dry cell weight; GO: Gene ontology; GPI: Glycosylphosphatidylinositol; GroPCho: Glycerophosphocholine; GroPIns: Glycerophosphoinositol; HPLC: High-performance liquid chromatography; P: Phosphate; PPP: Pentose phosphate pathway; ROS: Reactive oxygen species; TCA: Tricarboxylic acid; XDH: Xylitol dehydrogenase; XI: Xylose isomerase; XK: Xylulokinase; XR: Xylose reductase; YP: Yeast peptone.}

Competing interests

The authors declare that they have no competing interests.

\section{Authors' contributions}

AM participated in the design of the study, performed experimental work, and wrote the manuscript. TG performed the batch fermentations. TH participated in the design of the study and commented on the manuscript. All authors have read and approved the final manuscript.

\section{Acknowledgements}

This study was supported by the New Energy and Industrial Technology Development Organization (NEDO), Japan, and by the Japan-US cooperation project for research and standardization of Clean Energy Technologies. The authors thank Dr. Shigeki Sawayama (Kyoto University) and Dr. Katsuji 
Murakami (AIST) for their useful discussions, and Ms. Maiko Kato, Ms. Kanako Negi, and Ms. Shiori Morita for their technical assistance. We also thank Dr. Shingo Kikugawa and Dr. Motohiko Tanino (DNA Chip Research Inc.) for valuable support in performing the DNA microarray analysis.

\author{
Author details \\ ${ }^{1}$ Biomass Refinery Research Center (BRRC), National Institute of Advanced \\ Industrial Science and Technology (AIST), 3-11-32 Kagamiyama, \\ Higashi-Hiroshima, Hiroshima 739-0046, Japan. ${ }^{2}$ Graduate School of Life \\ Science, Hokkaido University, N10W8 Kita-ku, Sapporo, Hokkaido 060-0810, \\ Japan.
}

Received: 18 July 2013 Accepted: 24 January 2014

Published: 28 January 2014

\section{References}

1. Kevin AG, Lishan Z, Mark E: Bioethanol. Curr Opin Chem Biol 2006, 10:141-146.

2. Hahn-Hägerdal B, Karhumaa K, Fonseca C, Spencer-Martins I, Gorwa-Grauslund MF: Towards industrial pentose-fermenting yeast strains. Appl Microbiol Biotechnol 2007, 74:937-953.

3. Matsushika A, Inoue H, Kodaki T, Sawayama S: Ethanol production from xylose in engineered Saccharomyces cerevisiae strains: current state and perspectives. Appl Microbiol Biotechnol 2009, 84:37-53.

4. Van Vleet $\mathrm{JH}$, Jeffries TW: Yeast metabolic engineering for hemicellulosic ethanol production. Curr Opin Biotechnol 2009, 20:300-306.

5. Cai Z, Zhang B, Li Y: Engineering Saccharomyces cerevisiae for efficient anaerobic xylose fermentation: reflections and perspectives. Biotechnol J 2012, 7:34-46.

6. Matsushika A, Liu ZL, Sawayama S, Moon J: Improving biomass sugar utilization by engineered Saccharomyces cerevisiae. In Microbial Stress Tolerance for Biofuels. Volume 22. Edited by Liu ZL. Springer, Heidelberg, Germany: Microbiology Monographs; 2012:137-160.

7. Kötter P, Ciriacy M: Xylose fermentation by Saccharomyces cerevisiae. Appl Microbiol Biotechnol 1993, 38:776-783.

8. Tantirungkij M, Nakashima N, Seki T, Yoshida T: Construction of xyloseassimilating Saccharomyces cerevisiae. J Ferment Bioeng 1993, 75:83-88.

9. Bruinenberg PM, de Bot PHM, van Dijken JP, Scheffers WA: The role of redox balances in the anaerobic fermentation of xylose by yeasts. Eur J Appl Microbiol Biotechnol 1983, 18:287-292.

10. Walfridsson M, Bao X, Anderlund M, Lilius G, Bülow L, Hahn-Hägerdal B: Ethanolic fermentation of xylose with Saccharomyces cerevisiae harboring the Thermus thermophilus xylA gene, which expresses an active xylose (glucose) isomerase. Appl Environ Microbiol 1996, 62:4648-4651.

11. Kuyper M, Harhangi HR, Stave AK, Winkler AA, Jetten MS, de Laat WT, den Ridder JJ, Op den Camp HJ, van Dijken JP, Pronk JT: High-level functional expression of a fungal xylose isomerase: the key to efficient ethanolic fermentation of xylose by Saccharomyces cerevisiae? FEMS Yeast Res 2003, 4:69-78.

12. Lönn A, Träff-Bjerre KL, Cordero Otero RR, van Zyl WH, Hahn-Hägerdal B: Xylose isomerase activity influences xylose fermentation with recombinant Saccharomyces cerevisiae strains expressing mutated $x y / A$ from Thermus thermophilus. Enzyme Microb Technol 2003, 32:567-573.

13. Madhavan A, Tamalampudi S, Ushida K, Kanai D, Katahira S, Srivastava A, Fukuda H, Bisaria VS, Kondo A: Xylose isomerase from polycentric fungus Orpinomyces: gene sequencing, cloning, and expression in Saccharomyces cerevisiae for bioconversion of xylose to ethanol. Appl Microbiol Biotechnol 2009, 82:1067-1078.

14. Karhumaa K, Garcia Sanchez R, Hahn-Hägerdal B, Gorwa-Grauslund MF: Comparison of the xylose reductase-xylitol dehydrogenase and the xylose isomerase pathways for xylose fermentation by recombinant Saccharomyces cerevisiae. Microb Cell Fact 2007, 6:5.

15. van Maris AJ, Winkler AA, Kuyper M, de Laat WT, van Dijken JP, Pronk JT: Development of efficient xylose fermentation in Saccharomyces cerevisiae: xylose isomerase as a key component. Adv Biochem Eng Biotechnol 2007, 108:179-204

16. Kuyper M, Hartog MM, Toirkens MJ, Almering MJ, Winkler AA, van Dijken JP, Pronk JT: Metabolic engineering of a xylose-isomerase-expressing Saccharomyces cerevisiae strain for rapid anaerobic xylose fermentation. FEMS Yeast Res 2005, 5:399-409.

17. Zhou H, Cheng JS, Wang BL, Fink GR, Stephanopoulos G: Xylose isomerase overexpression along with engineering of the pentose phosphate pathway and evolutionary engineering enable rapid xylose utilization and ethanol production by Saccharomyces cerevisiae. Metab Eng 2012, 14:611-622

18. Demeke MM, Dietz H, Li Y, Foulquié-Moreno MR, Mutturi S, Deprez S, Den Abt T, Bonini BM, Liden G, Dumortier F, Verplaetse A, Boles E, Thevelein JM: Development of a D-xylose fermenting and inhibitor tolerant industrial Saccharomyces cerevisiae strain with high performance in lignocellulose hydrolysates using metabolic and evolutionary engineering. Biotechnol Biofuels 2013, 6:89.

19. Sedlak M, Edenberg HJ, Ho NWY: DNA microarray analysis of the expression of the genes encoding the major enzymes in ethanol production during glucose and xylose co-fermentation by metabolically engineered Saccharomyces yeast. Enzyme Microb Technol 2003, 33:19-28.

20. Wahlbom CF, Cordero Otero RR, van Zyl WH, Hahn-Hägerdal B, Jönsson L: Molecular analysis of a Saccharomyces cerevisiae mutant with improved ability to utilize xylose shows enhanced expression of proteins involved in transport, initial xylose metabolism, and the pentose phosphate pathway. App/ Environ Microbiol 2003, 69:740-746.

21. Salusjärvi L, Poutanen M, Pitkänen JP, Koivistoinen H, Aristidou A, Kalkkinen $N$, Ruohonen L, Penttilä M: Proteome analysis of recombinant xylose-fermenting Saccharomyces cerevisiae. Yeast 2003, 20:295-314.

22. Jin YS, Laplaza JM, Jeffries TW: Saccharomyces cerevisiae engineered for xylose metabolism exhibits a respiratory response. Appl Environ Microbiol 2004, 70:6816-6825.

23. Sonderegger $M$, Jeppsson M, Hahn-Hägerdal B, Sauer U: Molecular basis for anaerobic growth of Saccharomyces cerevisiae on xylose, investigated by global gene expression and metabolic flux analysis. Appl Environ Microbiol 2004, 70:2307-2317.

24. Salusjärvi L, Pitkänen JP, Aristidou A, Ruohonen L, Penttilä M: Transcription analysis of recombinant Saccharomyces cerevisiae reveals novel responses to xylose. Appl Biochem Biotechnol 2006, 128:237-261.

25. Salusjärvi L, Kankainen M, Soliymani R, Pitkänen JP, Penttilä M, Ruohonen L: Regulation of xylose metabolism in recombinant Saccharomyces cerevisiae. Microb Cell Fact 2008, 7:18.

26. Karhumaa K, Påhlman AK, Hahn-Hägerdal B, Levander F, Gorwa-Grauslund MF: Proteome analysis of the xylose-fermenting mutant yeast strain TMB 3400. Yeast 2009, 26:371-382

27. Runquist D, Hahn-Hägerdal B, Bettiga M: Increased expression of the oxidative pentose phosphate pathway and gluconeogenesis in anaerobically growing xylose-utilizing Saccharomyces cerevisiae. Microb Cell Fact 2009, 8:49.

28. Klimacek M, Krahulec S, Sauer U, Nidetzky B: Limitations in xylose-fermenting Saccharomyces cerevisiae, made evident through comprehensive metabolite profiling and thermodynamic analysis. Appl Environ Microbiol 2010, 76:7566-7574.

29. Bergdahl B, Heer D, Sauer U, Hahn-Hägerdal B, van Niel EW: Dynamic metabolomics differentiates between carbon and energy starvation in recombinant Saccharomyces cerevisiae fermenting xylose. Biotechnol Biofuels 2012, 5:34

30. Matsushika A, Nagashima A, Goshima T, Hoshino T: Fermentation of xylose causes inefficient metabolic state due to carbon/energy starvation and reduced glycolytic flux in recombinant industrial Saccharomyces cerevisiae. PLOS ONE 2013, 8:e69005.

31. Matsushika A, Inoue H, Murakami K, Takimura O, Sawayama S: Bioethanol production performance of five recombinant strains of laboratory and industrial xylose-fermenting Saccharomyces cerevisiae. Bioresour Technol 2009, 100:2392-2398.

32. Matsushika A, Sawayama S: Characterization of a recombinant flocculent Saccharomyces cerevisiae strain that co-ferments glucose and xylose: I. Influence of the ratio of glucose/xylose on ethanol production. Appl Biochem Biotechnol 2013, 169:712-721.

33. Hiser $L$, Basson ME, Rine J: ERG10 from Saccharomyces cerevisiae encodes acetoacetyl-CoA thiolase. J Biol Chem 1994, 269:31383-31389.

34. Basson ME, Thorsness M, Rine J: Saccharomyces cerevisiae contains two functional genes encoding 3-hydroxy-3-methylglutaryl-coenzyme A reductase. Proc Natl Acad Sci U S A 1986, 83:5563-5567.

35. Landl KM, Klösch $B$, Turnowsky F: ERG1, encoding squalene epoxidase, is located on the right arm of chromosome VII of Saccharomyces cerevisiae. Yeast 1996, 12:609-613.

36. Ashman WH, Barbuch RJ, Ulbright CE, Jarrett HW, Bard M: Cloning and disruption of the yeast C-8 sterol isomerase gene. Lipids 1991, 26:628-632. 
37. Andreasen AA, Stier TJ: Anaerobic nutrition of Saccharomyces cerevisiae. I. Ergosterol requirement for growth in a defined medium. J Cell Physiol 1953, 41:23-36.

38. Inoue T, lefuji H, Fujii T, Soga H, Satoh K: Cloning and characterization of a gene complementing the mutation of an ethanol-sensitive mutant of sake yeast. Biosci Biotechnol Biochem 2000, 64:229-236.

39. Mauricio JC, Moreno J, Zea L, Ortega JM, Medina M: The effect of grape must fermentation conditions on volatile alcohols and esters formed by Saccharomyces cerevisiae. J Sci Food Agr 1997, 75:155-160.

40. Thorsness M, Schafer W, D'Ari L, Rine J: Positive and negative transcriptional control by heme of genes encoding 3-hydroxy-3methylglutaryl coenzyme A reductase in Saccharomyces cerevisiae. Mol Cell Biol 1989, 9:5702-5712.

41. Kennedy MA, Barbuch R, Bard M: Transcriptional regulation of the squalene synthase gene (ERG9) in the yeast Saccharomyces cerevisiae. Biochim Biophys Acta 1999, 1445:110-122.

42. Tamura K, Gu Y, Wang Q, Yamada T, Ito K, Shimoi H: A hap1 mutation in a laboratory strain of Saccharomyces cerevisiae results in decreased expression of ergosterol-related genes and cellular ergosterol content compared to sake yeast. J Biosci Bioeng 2004, 98:159-166.

43. Rodríguez A, De La Cera T, Herrero P, Moreno F: The hexokinase 2 protein regulates the expression of the GLK1,HXK1 and HXK2 genes of Saccharomyces cerevisiae. Biochem J 2001, 355:625-631.

44. Delgado ML, O'Connor JE, Azorín I, Renau-Piqueras J, Gil ML, Gozalbo D: The glyceraldehyde-3-phosphate dehydrogenase polypeptides encoded by the Saccharomyces cerevisiae TDH1, TDH2 and TDH3 genes are also cell wall proteins. Microbiology 2001, 147:411-417.

45. Träff KL, Jönsson LJ, Hahn-Hägerdal B: Putative xylose and arabinose reductases in Saccharomyces cerevisiae. Yeast 2002, 19:1233-1241.

46. Richard P, Toivari MH, Penttilä M: Evidence that the gene YLR070c of Saccharomyces cerevisiae encodes a xylitol dehydrogenase. FEBS Lett 1999, 457:135-138

47. Juhnke H, Krems B, Kötter P, Entian KD: Mutants that show increased sensitivity to hydrogen peroxide reveal an important role for the pentose phosphate pathway in protection of yeast against oxidative stress. Mol Gen Genet 1996, 252:456-464.

48. Slekar KH, Kosman DJ, Culotta VC: The yeast copper/zinc superoxide dismutase and the pentose phosphate pathway play overlapping roles in oxidative stress protection. J Biol Chem 1996, 271:28831-28836.

49. Matsushika A, Goshima T, Fujii T, Inoue H, Sawayama S, Yano S: Characterization of non-oxidative transaldolase and transketolase enzymes in the pentose phosphate pathway with regard to xylose utilization by recombinant Saccharomyces cerevisiae. Enzyme Microb Technol 2012, 51:16-25.

50. Boy-Marcotte E, Lagniel G, Perrot M, Bussereau F, Boudsocq A, Jacquet M, Labarre J: The heat shock response in yeast: differential regulations and contributions of the Msn2p/Msn4p and Hsf1p regulons. Mol Microbiol 1999, 33:274-283.

51. Kelley R, Ideker T: Genome-wide fitness and expression profiling implicate Mga2 in adaptation to hydrogen peroxide. PLOS Genet 2009, 5:e1000488.

52. Forsburg SL, Guarente L: Identification and characterization of HAP4: a third component of the CCAAT-bound HAP2/HAP3 heteromer. Genes Dev 1989, 3:1166-1178

53. Gasch AP: The Environmental Stress Response: a common yeast response to environmental stresses. In Yeast Stress Responses. Volume 1 Edited by Hohmann S. Springer, Heidelberg, Germany: Topics in Current Genetics; 2002:11-70.

54. Boer VM, de Winde JH, Pronk JT, Piper MD: The genome-wide transcriptional responses of Saccharomyces cerevisiae grown on glucose in aerobic chemostat cultures limited for carbon, nitrogen, phosphorus, or sulfur. J Biol Chem 2003, 278:3265-3274.

55. Vallari RC, Cook WJ, Audino DC, Morgan MJ, Jensen DE, Laudano AP, Denis $\mathrm{CL}$ : Glucose repression of the yeast $A D H 2$ gene occurs through multiple mechanisms, including control of the protein synthesis of its transcriptional activator, ADR1. Mol Cell Biol 1992, 12:1663-1673.

56. Walther $\mathrm{K}$, Schüller HJ: Adr1 and Cat8 synergistically activate the glucose-regulated alcohol dehydrogenase gene $A D H 2$ of the yeast Saccharomyces cerevisiae. Microbiology 2001, 147:2037-2044.

57. Kratzer S, Schüller HJ: Transcriptional control of the yeast acetyl-CoA synthetase gene, ACS1, by the positive regulators CAT8 and ADR1 and the pleiotropic repressor UME6. Mol Microbio/ 1997, 26:631-641.
58. Buu LM, Chen YC, Lee FJ: Functional characterization and localization of acetyl-CoA hydrolase, Ach1p, in Saccharomyces cerevisiae. J Biol Chem 2003, 278:17203-17209.

59. Grauslund M, Lopes JM, Rønnow B: Expression of GUT1, which encodes glycerol kinase in Saccharomyces cerevisiae, is controlled by the positive regulators Adr1p, Ino2p and Ino4p and the negative regulator Opi1p in a carbon source-dependent fashion. Nucleic Acids Res 1999, 27:4391-4398.

60. Grauslund M, Rønnow B: Carbon source-dependent transcriptional regulation of the mitochondrial glycerol-3-phosphate dehydrogenase gene, GUT2, from Saccharomyces cerevisiae. Can J Microbiol 2000, 46:1096-1100.

61. Hamacher T, Becker J, Gárdonyi M, Hahn-Hägerdal B, Boles E: Characterization of the xylose-transporting properties of yeast hexose transporters and their influence on xylose utilization. Microbiology 2002, 148:2783-2788.

62. Reifenberger E, Boles E, Ciriacy M: Kinetic characterization of individual hexose transporters of Saccharomyces cerevisiae and their relation to the triggering mechanisms of glucose repression. Eur J Biochem 1997, 245:324-333.

63. Diderich JA, Schuurmans JM, Van Gaalen MC, Kruckeberg AL, Van Dam K: Functional analysis of the hexose transporter homologue HXT5 in Saccharomyces cerevisiae. Yeast 2001, 18:1515-1524.

64. Ozcan S, Johnston M: Function and regulation of yeast hexose transporters. Microbiol Mol Biol Rev 1999, 63:554-569.

65. Bengtsson O, Jeppsson M, Sonderegger M, Parachin NS, Sauer U, Hahn-Hägerdal B, Gorwa-Grauslund MF: Identification of common traits in improved xylose-growing Saccharomyces cerevisiae for inverse metabolic engineering. Yeast 2008, 25:835-847.

66. Wahlbom CF, van Zyl WH, Jönsson LJ, Hahn-Hägerdal B, Cordero Otero RR: Generation of the improved recombinant xylose-utilizing Saccharomyces cerevisiae TMB 3400 by random mutagenesis and physiological comparison with Pichia stipitis CBS 6054. FEMS Yeast Res 2003, 3:319-326.

67. Nehlin JO, Ronne H: Yeast MIG1 repressor is related to the mammalian early growth response and Wilms' tumour finger proteins. EMBO J 1990, 9:2891-2898.

68. Freese $\mathrm{EB}, \mathrm{Chu} \mathrm{MI}$, Freese E: Initiation of yeast sporulation of partial carbon, nitrogen, or phosphate deprivation. J Bacteriol 1982, 149:840-851.

69. Law DT, Segall J: The SPS100 gene of Saccharomyces cerevisiae is activated late in the sporulation process and contributes to spore wall maturation. Mol Cell Biol 1988, 8:912-922.

70. Briza $P$, Eckerstorfer $M$, Breitenbach $M$ : The sporulation-specific enzymes encoded by the DIT1 and DIT2 genes catalyze a two-step reaction leading to a soluble LL-dityrosine-containing precursor of the yeast spore wall. Proc Natl Acad Sci U S A 1994, 91:4524-4528.

71. Ishihara S, Hirata A, Nogami S, Beauvais A, Latge JP, Ohya Y: Homologous subunits of 1,3-beta-glucan synthase are important for spore wall assembly in Saccharomyces cerevisiae. Eukaryot Cell 2007, 6:143-156.

72. Nickas ME, Neiman AM: Ady3p links spindle pole body function to spore wall synthesis in Saccharomyces cerevisiae. Genetics 2002, 160:1439-1450.

73. Palková Z, Devaux F, Icicová M, Mináriková L, Le Crom S, Jacq C: Ammonia pulses and metabolic oscillations guide yeast colony development. Mol Biol Cell 2002, 13:3901-3914.

74. Martínez-Pastor MT, Marchler G, Schüller C, Marchler-Bauer A, Ruis H, Estruch F: The Saccharomyces cerevisiae zinc finger proteins Msn2p and Msn4p are required for transcriptional induction through the stress response element (STRE). EMBO J 1996, 15:2227-2235.

75. Schmitt AP, McEntee K: Msn2p, a zinc finger DNA-binding protein, is the transcriptional activator of the multistress response in Saccharomyces cerevisiae. Proc Natl Acad Sci U S A 1996, 93:5777-5782.

76. Simões T, Mira NP, Fernandes AR, Sá-Correia I: The SPI1 gene, encoding a glycosylphosphatidylinositol-anchored cell wall protein, plays a prominent role in the development of yeast resistance to lipophilic weak-acid food preservatives. Appl Environ Microbiol 2006, 72:7168-7175.

77. Kobayashi N, McClanahan TK, Simon JR, Treger JM, McEntee K: Structure and functional analysis of the multistress response gene DDR2 from Saccharomyces cerevisiae. Biochem Biophys Res Commun 1996, 229:540-547.

78. Winderickx J, de Winde JH, Crauwels M, Hino A, Hohmann S, Van Dijck P, Thevelein JM: Regulation of genes encoding subunits of the trehalose synthase complex in Saccharomyces cerevisiae: novel variations of STRE-mediated transcription control? Mol Gen Genet 1996, 252:470-482.

79. Pereira MD, Eleutherio EC, Panek AD: Acquisition of tolerance against oxidative damage in Saccharomyces cerevisiae. BMC Microbiol 2001, 1:11. 
80. Patton-Vogt JL, Henry SA: GIT1, a gene encoding a novel transporter for glycerophosphoinositol in Saccharomyces cerevisiae. Genetics 1998, 149:1707-1715.

81. Fisher E, Almaguer C, Holic R, Griac P, Patton-Vogt J: Glycerophosphocholinedependent growth requires Gde1p (YPL110c) and Git1p in Saccharomyces cerevisiae. J Biol Chem 2005, 280:36110-36117.

82. Singleton CK: Identification and characterization of the thiamine transporter gene of Saccharomyces cerevisiae. Gene 1997, 199:111-121.

83. Hauser M, Narita V, Donhardt AM, Naider F, Becker JM: Multiplicity and regulation of genes encoding peptide transporters in Saccharomyces cerevisiae. Mol Membr Biol 2001, 18:105-112.

84. Kolarov J, Kolarova N, Nelson N: A third ADP/ATP translocator gene in yeast. J Biol Chem 1990, 265:12711-12716.

85. Macreadie IG, Novitski CE, Maxwell RJ, John U, Ooi BG, McMullen GL, Lukins HB, Linnane AW, Nagley P: Biogenesis of mitochondria: the mitochondrial gene (aap1) coding for mitochondrial ATPase subunit 8 in Saccharomyces cerevisiae. Nucleic Acids Res 1983, 11:4435-4451.

86. Marzuki S, Watkins LC, Choo WM: Mitochondrial $\mathrm{H}^{+}$-ATPase in mutants of Saccharomyces cerevisiae with defective subunit 8 of the enzyme complex. Biochim Biophys Acta 1989, 975:222-230.

87. Matsushika A, Inoue H, Watanabe S, Kodaki T, Makino K, Sawayama S: Efficient bioethanol production by recombinant flocculent Saccharomyces cerevisiae with genome-integrated $\mathrm{NADP}^{+}$-dependent xylitol dehydrogenase gene. Appl Environ Microbiol 2009, 75:3818-3822.

88. Matsushika A, Watanabe S, Kodaki T, Makino K, Inoue H, Murakami K, Takimura O, Sawayama S: Expression of protein engineered $\mathrm{NADP}^{+}$-dependent xylitol dehydrogenase increase ethanol production from xylose in recombinant Saccharomyces cerevisiae. Appl Microbiol Biotechnol 2008, 81:243-255.

89. Bergdahl B, Sandström AG, Borgström C, Boonyawan T, van Niel EW, Gorwa-Grauslund MF: Engineering yeast hexokinase 2 for improved tolerance toward xylose-induced inactivation. PLOS ONE 2013, 8:e75055.

90. Iwahashi H, Kitagawa E, Suzuki Y, Ueda Y, Ishizawa YH, Nobumasa H, Kuboki $Y$, Hosoda H, Iwahashi Y: Evaluation of toxicity of the mycotoxin citrinin using yeast ORF DNA microarray and Oligo DNA microarray. BMC Genomics 2007, 8:95.

91. Hirasawa T, Ookubo A, Yoshikawa K, Nagahisa K, Furusawa C, Sawai H, Shimizu H: Investigating the effectiveness of DNA microarray analysis for identifying the genes involved in L-lactate production by Saccharomyces cerevisiae. Appl Microbiol Biotechnol 2009, 84:1149-1159.

92. Ueda Y, Ikushima S, Sugiyama M, Matoba R, Kaneko Y, Matsubara K, Harashima S: Large-scale genome reorganization in Saccharomyces cerevisiae through combinatorial loss of mini-chromosomes. J Biosci Bioeng 2012, 113:675-682.

93. Workman $C$, Jensen $L$, Jarmer $H$, Berka R, Gautier L, Nielser HB, Saxild HH, Nielsen C, Brunak S, Knudsen S: A new non-linear normalization method for reducing variability in DNA microarray experiments. Genome Biol 2002, 3:research0048

doi:10.1186/1475-2859-13-16

Cite this article as: Matsushika et al:: Transcription analysis of recombinant industrial and laboratory Saccharomyces cerevisiae strains reveals the molecular basis for fermentation of glucose and xylose. Microbial Cell Factories 2014 13:16.

\section{Submit your next manuscript to BioMed Central and take full advantage of:}

- Convenient online submission

- Thorough peer review

- No space constraints or color figure charges

- Immediate publication on acceptance

- Inclusion in PubMed, CAS, Scopus and Google Scholar

- Research which is freely available for redistribution

Submit your manuscript at www.biomedcentral.com/submit
C Biomed Central 